\title{
Guidelines
}

\section{Consensus Guidelines for the Selection and Implantation of Patients With Noncancer Pain for Intrathecal Drug Delivery}

Timothy R. Deer, MD, Howard S. Smith, MD², Michael Cousins, MD³, Daniel M. Doleys, PhD, Robert M. Levy, MD, PhD ${ }^{5}$, James P. Rathmell, MD ${ }^{6}$, Peter S. Staats, $\mathrm{MD}^{7}$, Mark Wallace, $\mathrm{MD}^{8}$, and Lynn R. Webster, MD9

From: ${ }^{1}$ Center for Pain Relief, Inc, Charleston, West Virginia; ${ }^{2}$ Albany Medical College, Albany, New York; ${ }^{3}$ Royal North Shore Hospital, St. Leonards, Australia; "Pain and Rehabilitation Institute, Birmingham, AL; ${ }^{5}$ Northwestern University Feinberg School of Medicine, Chicago, IL; ${ }^{6}$ Massachusetts General Hospital/Harvard Medical School, Boston, MA; ${ }^{7}$ Metzger Pain Management, Shrewsbury, NJ; ${ }^{8}$ University of California, San Diego, CA; ${ }^{2}$ Lifetree

Clinical Research and Pain Clinic, Salt Lake City, UT

Dr Deer is with the Center for Pain Relief, Inc, Charleston, WV; Dr. Smith is with the Albany Medical College, Albany, NY; Dr. Cousins is with the Royal North Shore Hospital, St. Leonards, Australia; Dr. Doleys is with the Pain and Rehabilitation Institute, Birmingham, AL; Dr. Levy is with Northwestern University Feinberg School of Medicine, Chicago, IL; Dr. Rathmell is with Massachusetts General Hospital/ Harvard Medical School, Boston, MA; Dr. Staats is with Metzger Pain Management, Shrewsbury, NJ: Dr. Wallace is with the University of California, San Diego, CA; Dr. Webster is with Lifetree Clinical Research and Pain Clinic, Salt Lake City, UT.

Address correspondence: Timothy R. Deer, MD, The Center for Pain Relief, Inc. 400 Court Street, Suite 302

Charleston, West Virginia 25301 E-mail: DocTDeer@aol.com

Disclaimer: See complete information on p. E207.

Manuscript received: Accepted for publication:

Free full manuscript: www.painphysicianjournal.com
Intrathecal therapy offers an invasive alternative for the long-term management of select patients with intractable pain associated with various disease states, including those of noncancer origin. It is commonly accepted that proper patient selection is essential to optimizing treatment outcomes, yet the practice of candidate selection for device implantation varies widely. A multifaceted approach —with consideration of preexisting medical comorbidities; psychological status; associated social, technical, and economic issues; and response to intrathecal trialing-enables practitioners to fully evaluate the appropriateness of implanting a patient with an intrathecal drug delivery system. Yet, to date no standard set of guidelines have been developed to aid practitioners in navigating this evaluation process.

Using experience- and knowledge-based expert opinion to systematically evaluate the available evidence, this article provides consensus guidelines aimed at optimizing the selection of patients with noncancer pain for intrathecal therapy.

In conclusion, complete assessment of a patient's physical, psychological, and social characteristics, can guide practitioners in determining the appropriateness of initiating intrathecal therapy. These consensus guidelines are intended to assist with weighing this risk/benefit ratio of intrathecal therapy, thereby minimizing the potential for treatment failure, unacceptable adverse effects, and excess mortality.

Key words: Chronic pain, noncancer pain, opioids, intrathecal drug delivery systems, guidelines, consensus guidelines

Pain Physician 2010; 13: E175-E213

\subsection{InTRODUCTION}

$D$ ersistent pain is one of the most common and pervasive problem in modern medicine (1). Chronic pain and chronic pain syndrome have been defined in many ways, however, chronic persistent pain is different from chronic pain syndrome which is a separate entity. Chronic pain is defined as, "pain that persists 6 months after an injury and beyond the usual course of an acute disease or a reasonable time for a comparable injury to heal, that is associated with chronic pathologic processes that 
cause continuous or intermittent pain for months or years, that may continue in the presence or absence of demonstrable pathologies; may not be amenable to routine pain control methods; and healing may never occur (1)." However, chronic pain syndrome, in contrast, has been defined as a complex condition with physical, psychological, emotional, and social components. The effects of chronic pain are broad and may be profound with significant impairment of physical and psychological health and performance of social responsibilities including work and family (1). Despite improvements in the understanding of pain including diagnosis and treatment, chronic pain continues to be an epidemic and is coupled with claims of inadequate treatment. The prevalence of chronic pain in the adult population ranges from $2 \%$ to $40 \%$, with a median point prevalence of $15 \%$. Enormous increase of chronic pain over the years has been demonstrated $(1,2)$.

Interventional pain management has been advanced based on the discoveries of chemical mediation and the development and understanding of precision diagnostic and therapeutic interventional techniques, together with reported successes with minimally invasive treatments, including spinal cord stimulation and intrathecal implantable infusion systems (3-9).

\subsection{Intrathecal Drug Delivery Systems}

Intrathecal (IT) drug delivery systems offer an invasive alternative for the long-term management of select patients with intractable pain associated with various disease states, including failed back surgery syndrome, complex regional pain syndrome, spinal stenosis, osteoporosis with compression fractures, and peripheral neuropathies $(10,11)$. In contrast to other noninvasive therapeutic strategies for pain, IT drug delivery may improve efficacy and tolerability through the employment of innovative techniques; a drug delivery pump contains and delivers analgesic medication to the spinal receptors through a connected catheter strategically placed into the cerebrospinal fluid (CSF). The site of action within the CSF is influenced by the catheter location and the lipophilicity of the selected IT agent. Clinical benefit is achieved by an increased pharmacologic effect attributable to direct action at spinal receptors and reduced drug delivery to the brain via the blood-brain barrier, while patients gain the advantage of greater independence and lower risk of infection than with external or partially externalized systems (12).

\subsection{Rationale}

The expertise of a skilled physician for the placement of the device and perioperative management is essential to minimize risks (13). Despite use of preventive measures, perioperative complications-including infection, bleeding, drug mishaps, and device complications-have been associated with the procedure (14). Additional post-implantation adverse outcomes, such as failure to produce acceptable pain relief or improvement in function, can be minimized through rigorous patient selection and the use of tailored drug algorithms (15). However, failure to attain satisfactory results with IT drug delivery remains all too common, and in the worst-case scenario, can lead to removal of the device.

Patient selection for treatment with IT drug delivery remains empiric and varies widely among practitioners. Nonetheless, there are multiple clues in the available scientific literature that may well guide the standardization of patient selection for IT therapy, an intervention typically considered after exhaustion of more conservative means of treatment.

\subsection{Methodology of Guideline Developiment}

Clinical guidelines are a constructive response to the reality that practicing physicians require assistance into assimilating and applying the exponentially expanding, often contradictory, body of medical knowledge $(16,17)$. Clinical practice guidelines attempt to define practices that meet the needs of most patients under most circumstances, however, they must not attempt to supplant the independent judgement of clinicians in responding to particular clinical situations (18). Ideally, the specific clinical recommendations that are contained within the practice guidelines have been systematically developed by panels of experts who have access to the available evidence, have an understanding of the clinical problem, and have clinical experience with the subject, procedure, and the relevant research methods to make considered judgements. Consequent$l y$, these panels must be objective and must produce recommendations that are unbiased, up-to-date, and free from conflict of interest. While most guidelines are widely perceived as evidence-based, some guidelines are based on the consensus or authority and may be considered to have bias and lack validity.

Multiple guidelines have been developed in interventional pain management $(3,16)$. There are multiple 
issues related to the development of guidelines along with controversies. ASIPP launched the development of practice guidelines for interventional techniques in the management of chronic pain and published multiple updates $(3,16)$. ASIPP has utilized evidence-based guideline process with systematic reviews $(11,16,19-41)$. However, for selection and implantation of patients with non-cancer pain for intrathecal drug delivery, evidence-based development of guidelines is not feasible. The systematic review by Patel et al (11) was unable to find any randomized trials evaluating the effectiveness of intrathecal infusion systems on a long-term basis. Consequently, a decision was made to develop consensus guidelines.

The consensus group was chosen based on previous publications, academic achievement, geographic diversity and specialty diversity. The project was developed by Dr. Deer and Dr. Smith, the guideline co-chairs, and faculty was chosen based on their unanimous consent. The chairmen obtained an unrestricted grant from the Inset Corporation, who had no input on the content of the guides. The initial meeting was held during the
World Institute of Pain's International Meeting in New York City. The panel conducted a review of the world literature using PubMed, EMBASE, and Google Scholar from 1966 to December 2009. The inclusion of each article was based on the judgment of the panel as to the scientific merit and importance to patient selection. The consensus guidelines are undertaken to provide guidance for intrathecal infusion systems. However, systematic assessment of the quality of individual manuscripts was not performed.

\subsection{Overview of Clinical Experience}

Advances in IT therapy-in combination with the wide variety of available agents as outlined in Fig. 1-have offered an alternative means to provide pain relief for patients with intractable pain inadequately relieved by standard medical management (15). When considering an individualized, multidimensional approach to patient selection, revisiting the published literature is essential to establish the risk/benefit ratio required to develop appropriate guidelines for longterm therapy.

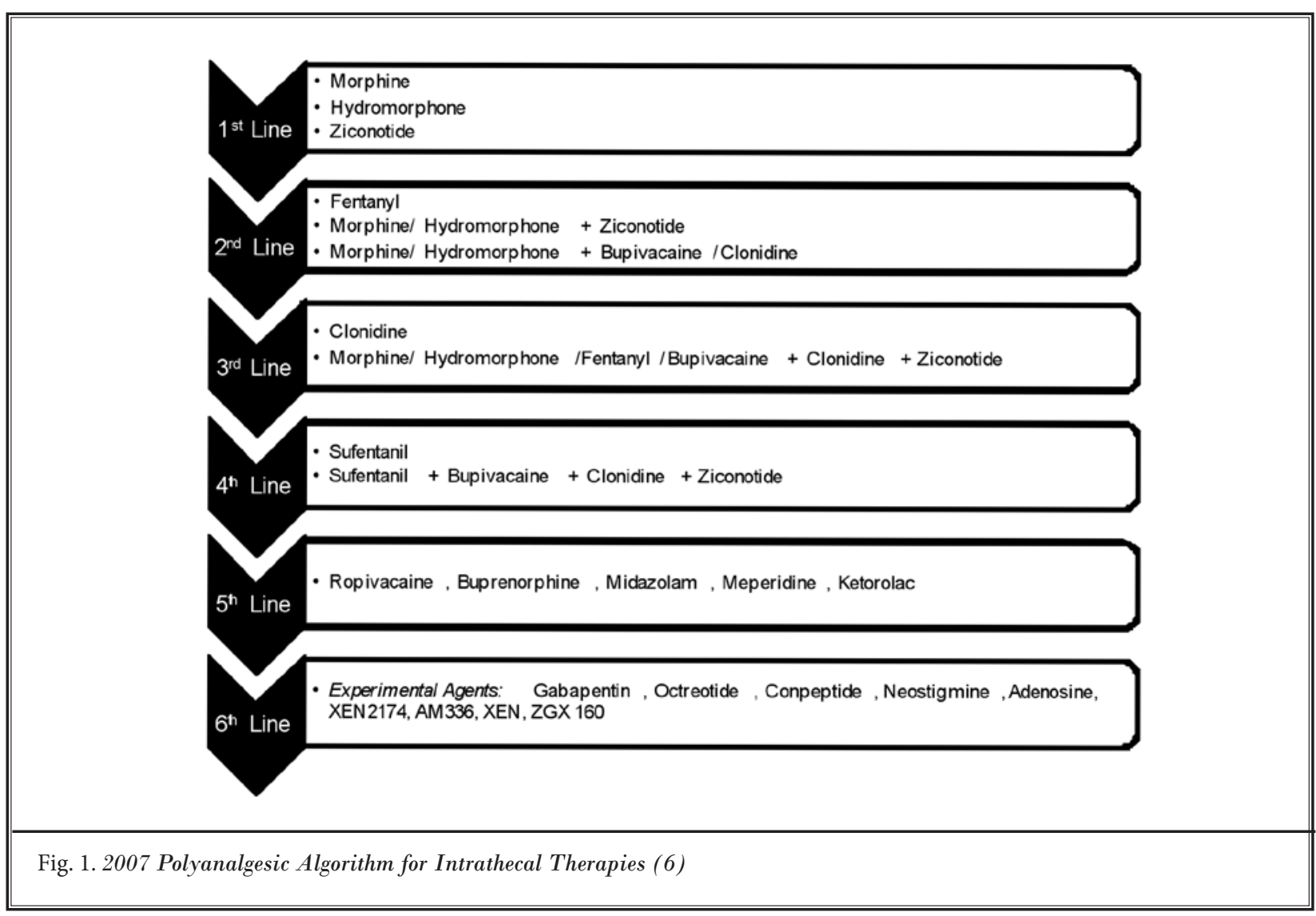




\subsection{Therapeutic Success and Treatment Limitations}

Over the past decade, numerous prospective and/or randomized controlled trials have evaluated the use of the IT infusion modality in patients with noncancer pain in a variety of settings and patient populations (42-47). IT therapy for noncancer pain has largely been found to reduce pain severity, and evidence of analgesic response has been demonstrated in patients with neuropathic, visceral, deafferentation, or mixed pain (42-49). However, the variable nature of the agents used and patient populations included in these studies complicates the interpretation of data, as compared with other medical devices or anesthetic monotherapy. Furthermore, investigators often vary in how they administer drugs, with some using low flow, high flow, pulsed infusion, or variable rates. Although many of these studies successfully replicate real-world practice, they do not allow for easy interpretation or for generalizations to be made across patient populations. More recently, specific drugs and drug combinations have been studied as independent variables to better ascertain the effect of therapy (5055). Most of these studies further support the efficacy of IT therapy for reducing pain intensity (50-55); yet, other trials have reported that not all IT treatment regimens produce optimal results $(52,53)$. Turner and colleagues performed a systematic review of effectiveness and complications for programmable IT opioid delivery systems for chronic noncancer pain and found improvement in pain and functioning for patients with permanently implanted IT drug delivery systems (56). Noble et al conducted a systematic review and meta-analysis and concluded that a subpopulation of individuals with chronic noncancer pain achieved long-term analgesia with IT opioids (57). In the absence of more definitive findings, practitioners have largely relied on good clinical judgment to guide them through the selection process and long-term management of patients with intractable noncancer pain (10).

There is only limited evidence to validate the benefits of IT drug delivery on physical and mental functioning (58-60). Results from a 3-year prospective study by Thimineur et al (46) reported that pump recipients had improvements in pain, mood, and function from baseline to 36 months. In comparison, nonrecipients-those who either failed an IT trial or declined pump implantation-showed substantial worsening with respect to physical function, depression, and anxiety scores (46). An improvement in physical functioning was also demonstrated in an analysis of the National Outcomes Reg- istry for Low Back Pain (47). In this study, $60 \%$ of those who received treatment through a drug delivery device showed improvement in their Oswestry score at a 6month follow-up; this number increased to $66 \%$ when pump recipients were evaluated at a 12-month followup (47). Although these data suggest a possible correlation between IT therapy and improvement in physical and mental functioning, the prospective design of the studies prohibits absolute confirmation of such outcomes. Controlled trials are warranted to substantiate this potential benefit of intraspinal drug therapy.

Despite widespread clinical use, a recent review of the available literature performed by Smith et al (61) concluded that the role of implantable drug delivery devices for the management of persistent noncancer pain remains ill-defined with a need to better determine appropriate patient selection. Patel et all (11) in a systematic review found only limited evidence.

Although an accumulation of data strongly supports the use of IT therapy for cancer-related pain, additional trials are needed to determine the most appropriate pain conditions and/or subpopulation of patients with noncancer pain best suited for treatment with an implantable drug delivery system (61). Regardless, the researchers found reasonably strong evidence supporting the short-term use of IT therapy for treatment of cancer and neuropathic pain; evidence supporting the use of long-term therapy for intractable noncancer pain was not as robust $(60,61)$.

\subsection{Clinical Implications of IT Drug Delivery.}

Adverse effects and complications of IT therapy are also well documented in the literature. Studies have identified the emergence of issues related to dose escalation, specifically acknowledging IT granulomas and excess mortality as potential consequences of IT drug delivery $(15,61,62)$. To maximize the effects of treatment without compromising patient safety, it is essential that clinicians are aware of these potential issues and recognize patients most at risk for complications of long-term IT therapy (62).

The potential consequences of inappropriate dosing/titration were noted in the 2007 Interdisciplinary Polyanalgesic Conference recommendations (5). IT therapy has been associated with severe adverse effects, including opioid-induced hyperalgesia, hypotension, sedation, and respiratory depression; opioids may also cause hypogonadotrophic hypogonadism, which potentially can result in sexual dysfunction and osteoporosis $(63,64)$. Even more concerning, escalation of dosage 
that occurs too quickly and without proper monitoring-particularly during the initial 24 hours following device implantation-can result in excess mortality $(65,66)$. Acknowledging that most IT agents have doserelated adverse effects, the panel recommended starting low and slowly increasing the dosage, as required, based on patient response (15). Notably, clinicians may consider accelerating dose changes in patients who are young and robust; however, caution should be used when titrating doses for those who are old and frail, adjusting administration only weekly. To further minimize the potential for adverse effects, the panel suggested that titration not exceed the recognized upper dosing limits for each agent unless a complicated medical decision is needed (15).

When dose escalation reaches its limit with monotherapy, clinicians have combined agents to provide continued analgesia. Based on data from animal studies, combination therapy demonstrates the potential to produce synergistic antinociception $(67,68)$. Additionally, combination therapy may allow for lower dosages of each agent, thus reducing the possibility for adverse effects associated with higher administration rates (69). The safety and efficacy of combination therapy has been evaluated in many clinical studies, the findings of which support the combined use of opioids (morphine or hydromorphone) and bupivacaine, morphine and clonidine, and morphine and ziconotide for the treatment of noncancer pain $(15,50,55,69)$.

For patients receiving high dosages of IT medication, sudden cessation of drug-due to catheter disruption, battery failure, or human error-can also result in severe and sometimes fatal adverse effects (70). Abrupt disruption or discontinuation of clonidine, for instance, may result in rebound hypertension and increase the risk for stroke in patients previously receiving high-dose therapy $(15,61,71)$. IT baclofen withdrawal can also be life-threatening, with reports of respiratory depression, hyperthermia, disseminated intravascular coagulation, acute renal failure, and acute multiorgan failure (61.62).

Findings in the literature suggest that dose and subsequent concentration escalation contributes to the development of IT granulomas. An online survey by Deer et al found catheter-tip inflammatory masses to be a relatively common occurrence, with $63.9 \%$ of respondents indicating that they had treated at least 1 patient who developed a granuloma secondary to IT therapy (72). In a review of published and unpublished case reports, Hassenbusch et al concluded that IT gran- ulomas occurred only in patients who received IT opioids-alone or mixed with other agents-or in patients treated with agents that were not approved for longterm IT delivery (73). In fact, inflammatory masses have been attributed to the use of all agents in implantable devices, with the exception of ziconotide, sufentanil and fentanyl (15). Timely diagnosis of a catheter-tip inflammatory mass-symptoms of which include the loss of analgesic effect in addition to new and progressive neurologic symptoms-allows for minimally invasive therapy and may prevent the need for surgical removal of the mass (73); if left untreated, IT granulomas can lead to long-term neurologic damage and permanent paralysis (62).

\subsection{Patient Selection Guidelines.}

A risk/benefit ratio can be extrapolated from the existing literature, focusing on both effective therapeutic interventions, as well as on the possible implications of therapy. Although practitioners will agree that proper patient selection is paramount to successful treatment, to date there is substantial variation in the ways in which IT candidates are chosen (44). Guidelines, therefore, are needed to assist clinicians in selecting appropriate recipients for device implantation.

\subsection{Diagnosistic Considerations}

Preliminary evaluation for IT therapy relies on the ability of the clinician to accurately identify nociceptive and/or neuropathic factors contributing to the patient's pain, with a view toward identifying potential pathophysiologies consistent with chronic pain $(13,74)$. Diagnostic assessment of the patient with chronic noncancer pain should encompass a complete physical, neurologic, radiologic, psychological, and social evaluation $(62,74)$. A detailed pain history and a review of the patient's medical records, prior pharmacologic treatments, and laboratory findings should be incorporated into the evaluation (74). Common disease states and diagnoses for which IT drug delivery is indicated include neuropathic pain syndromes (eg, thalamic syndrome, spinal cord injury, diabetic neuropathy, or postherpetic neuralgia); radicular pain from failed back surgery syndrome; complex regional pain syndrome; osteoporosis; pancreatitis; phantom limb pain syndrome; compression fractures; and other disorders caused by injury or irritation to the nervous system $(62,74)$. Unlike pain associated with terminal illness, noncancer pain patients tend to have longer life spans and require extended therapy that can range from months to years (74). 
The type of pain a patient reports-typically classified as visceral/somatic nociceptive, neuropathic, or mixed neuropathic nociceptive pain-may impact therapeutic outcomes, as response to IT delivery can vary depending on the pain presentation (74). However, there is no definitive evidence as to which pain type is best suited for treatment with an implantable device (74). Patients with visceral nociceptive pain or somatic nociceptive pain often respond well to IT therapy (74). Limited evidence suggests that patients with nociceptive pain may achieve a greater therapeutic effect than those with neuropathic or mixed nociceptive/neuropathic pain. For example, a multicenter, retrospective study of 429 patients receiving IT therapy found that patients with nociceptive pain tended to experience greater relief than those with neuropathic or mixed pain; notably, this study was not designed specifically for this purpose (49). Yet, other research has demonstrated that neuropathic pain is responsive to IT therapy. A retrospective observational study of 120 patients with chronic noncancer pain syndromes found that long-term IT therapy reduced neuropathic pain by an average of $62 \%$; only patients with deafferentation pain had better results, reporting a $68 \%$ reduction in pain as measured by the visual analog scale (48). Patients with mixed nociceptive/neuropathic pain are typically the most difficult to treat successfully, often necessitating the use of combination therapy to achieve effective analgesia $(47,74)$.

Pain intensity should also be assessed as part of the diagnostic evaluation (74). Numerous tools-including numerical pain rating scales, visual analog scales, verbal rating scales, faces pain rating scales, and pain questionnaires-are available to assist clinicians in assessing and quantifying pain intensity $(74,75)$. An accurate measure of pain intensity is important not only during the patient selection process, but throughout treatment since it serves as a baseline calculation from which to determine the continuing effect of therapy. The majority of research studies involving IT therapy include pain severity as an inclusion criterion to provide a basis for evaluating comparative efficacy across trial participants. Pain intensity also has an important impact on treatment outcomes; although patients with greater pain severity may achieve a reduction in pain level via IT drug delivery, the overall pain intensity may remain high compared with individuals who present with a lesser magnitude of initial pain (46).

A final consideration during the diagnostic evaluation takes into account the substantial impact chronic pain has on functional ability and quality of life. Pa- tients who demonstrate significant limitations as a result of chronic pain-including those manifesting with psychological disturbances, poor appetite and weight loss, decreases in physical and recreational activities, sleep disturbances, or a change in interpersonal relationships and economic stability-should be considered for IT therapy (74). Successful treatment outcomes may afford the patient the opportunity to return to activities of daily living, thus improving quality of life, although improved function may require additional measures (eg, cognitive behavioral therapy [CBT]) (59).

\subsection{Panel Recommendations.}

Identifying nociceptive and/or neuropathic factors in chronic noncancer pain is critical to ensuring proper patient selection. Patients with nociceptive pain are ideal candidates for IT therapy, although research suggests that therapy can also be effective for patients with neuropathic and mixed nociceptive/neuropathic pain. Given the risks associated with implanted drug delivery systems, pain intensity and its impact on functionality and quality of life should also be considered during the evaluation process. If pain is reduced but function does not improve, the addition of CBT should be considered (59).

\subsection{Associated Medical Comorbidities}

Patients with chronic noncancer pain often have coexisting medical conditions. The number and complexity of these comorbidities increase with age; the average elderly patient suffers from at least 4 concurrent medical problems $(76,77)$. These coexisting medical conditions influence the pain experience and overall outcomes associated with pain treatment (76).

\subsection{Diabetes Mellitus.}

In 2007, diabetes affected approximately $8 \%$ of the US population-23.6 million individuals - with an additional 57 million patients having blood glucose levels indicative of prediabetes $(78,79)$. An estimated $60 \%$ to $70 \%$ of diabetic individuals experience some form of nervous system damage, with peripheral neuropathy being among the most severe complications of diabetes (80). Risk factors for neuropathy include having had diabetes for more than 25 years, poor glucose control, hypertension, and obesity (80). According to a survey of 993 patients with diabetes, $60 \%$ of respondents indicated that they experienced chronic pain, many of whom reported difficulty in managing their medications, as well as reduced activities of daily living (81). 
There is no evidence to help us better understand the role of IT drug therapy in treating pain associated with diabetes or the relative risk of treating a diabetic patient versus nondiabetics. Nonetheless, it is clear that poor wound healing and an increased rate of surgical site infections occur in this patient population (82). This is especially important as wound infection is the most common device-related complication associated with implanted drug delivery systems (83). There is also sound evidence that patients who undergo surgery with better long-term glycemic control-as evidenced by lower hemoglobin A1c levels immediately prior to surgery-have lower rates of surgical site infection and other morbidity and mortality rates (84). Thus, the panel recommends that diabetic patients, particularly those with poor glycemic control, be counseled regarding the increased risk of surgical site infection and that this potential consequence of surgery be carefully considered in the overall risk/benefit discussion. The escalated risk of wound infection in diabetics also warrants increased vigilance for signs and symptoms of evolving wound infection after implantation. Although there are reports of successful resolution of surgical site infections in patients receiving IT therapy using local incision and drainage, meticulous wound care, and systemic antibiotics aimed at the inciting organism, the majority of cases will require explantation of the device to effectively eradicate infection (85).

\subsection{Coagulopathies and Anticoagulant Therapy}

Anticoagulant and antiplatelet therapy have become commonplace in the long-term management of many disorders, including atherosclerotic coronary artery disease. Hospitalized patients frequently receive systemic treatment with heparin and heparin analogues; ambulatory patients often receive long-term therapy with warfarin or an increasing array of potent platelet inhibitors. Specific pain management concerns for anticoagulated patients influence perioperative anesthesia- and analgesia-related safety decisions surrounding device implantation; as a result, regional anesthesia is typically avoided due to the risk of neurologic complications unless the patient is able to discontinue use of anticoagulants preoperatively (86). Patients receiving anticoagulants are also at an increased risk for the development of spinal epidural hematoma during epidural catheter insertion or following catheter removal $(86,87)$. Despite an estimated incidence of 1:220,000 and 1:150,000 following IT and epidural instrumentation, respectively, spinal hematomas were found to comprise almost half of the reported spinal cord injuries and were the primary source of malpractice claims in the American Society of Anesthesiologists Closed Claims database during the 1990 s $(86,87)$. Assessment of systemic factors and associated medications that might influence intraoperative coagulation is critical to minimize surgical complications (88).

According to the Joint Commission, anticoagulants are one of the 5 leading classes of drugs that contribute to avoidable compromises in patient safety in the United States (89). Following the introduction of low-molecularweight heparin (LMWH), a series of reports of patients who developed epidural hematomas and catastrophic neural injuries following neuraxial blockade (typically epidural anesthesia) appeared (86). This led the US Food and Drug Administration (FDA) to add a black box warning to the drug label for $\mathrm{LMWH}$, cautioning against the conduct of neuraxial anesthesia in patients receiving this agent (86). Thereafter, the elevated risk of bleeding associated with a wide array of anticoagulant and antiplatelet agents has been systematically reviewed by the American Society of Regional Anesthesia and Pain Medicine (Table 1) $(62,86)$. When considering patients for initial placement of a trial IT catheter or permanent implanted drug delivery system, the panel recommends following these well-established guidelines.

The risk of reinitiating chronic anticoagulant therapy following placement of a permanent IT drug delivery system is unknown. Nonetheless, the panel consensus is that the need for chronic anticoagulation is not an absolute contraindication to the use of IT therapy.

\subsection{Immunocompromised Patients}

Studies have examined the safety and efficacy of IT therapy in patients with advanced medical illness and significant compromise of their immune systems, including individuals with cancer and acquired immunodeficiency syndrome (AIDS) $(54,90)$. Although it is uncertain at present whether immune compromise independently increases the rate of IT therapy failure due to device infection, reported device infection rates are similar between immunocompromised patient populations (eg, those with cancer or AIDS) and all treated individuals based on indirect comparative data $(54,83,91)$; however, logic suggests that a compromised immune system may elevate the risk of infection. In the absence of conclusive data, the panel recommends careful evaluation of potential risks and benefits when considering IT therapy for patients manifesting with significant immune compromise. 
Table 1. Recommendations for Neuraxial Anesthesia in Patients Receiving Thromboprophylaxis (27)

\begin{tabular}{|c|c|c|}
\hline Drug or Drug Class & Bleeding Risk & Recommendation \\
\hline Unfractionated heparin & $\begin{array}{l}\text { No increased risk with neuraxial } \\
\text { blockade; risk of heparin-induced thrombocy- } \\
\text { topenia with administration for } \geq 4 \text { days }\end{array}$ & $\begin{array}{l}\text { Subcutaneous heparin ( } 5000 \text { units every } 12 \\
\text { hour) for DVT prophylaxis; remove indwell- } \\
\text { ing neuraxial catheters } 2 \text { - } 4 \text { hours after last } \\
\text { heparin dose }\end{array}$ \\
\hline LMWHs & $\begin{array}{l}\text { Moderate risk with single daily dose for DVT } \\
\text { or PE treatment and thromboprophylaxis; high } \\
\text { risk with combination of antiplatelet or oral } \\
\text { anticoagulant medications }\end{array}$ & $\begin{array}{l}\text { LMWHs should be held } 24 \text { hours before } \\
\text { surgery and resumed } 8 \text { - } 12 \text { hours postopera- } \\
\text { tively; consider placement of an inferior vena } \\
\text { cava filter before surgery for patients at high } \\
\text { risk for PE; } \\
\text { oral anticoagulants may be restarted } 12 \text { hours } \\
\text { after surgery }\end{array}$ \\
\hline Warfarin & $\begin{array}{l}\text { Spinal puncture and lumbar blockade contrain- } \\
\text { dicated; high risk with combination of LMWH, } \\
\text { heparin, or antiplatelet medications }\end{array}$ & $\begin{array}{l}\text { Discontinue } 4-5 \text { days before surgery; INR } \\
\text { must be }<1.5 \text { before surgery; warfarin } 5 \mathrm{mg} \\
\text { can be resumed immediately after surgery and } \\
\text { adjusted to INR of } 2.0-3.0\end{array}$ \\
\hline NSAIDs & $\begin{array}{l}\text { No significant increase in risk as } \\
\text { monotherapy; high risk with } \\
\text { combination of anticoagulant or } \\
\text { antiplatelet medications }\end{array}$ & $\begin{array}{l}\text { No specific recommendations; switch to } \\
\text { COX-2 inhibitor for patients requiring anti- } \\
\text { inflammatory therapy }\end{array}$ \\
\hline Ticlopidine, clopidogrel & $\begin{array}{l}\text { Risk based on history of easy bruising, excessive } \\
\text { bleeding, female sex, and increased age; in- } \\
\text { creased risk with combination of anticoagulant } \\
\text { or antiplatelet medications }\end{array}$ & $\begin{array}{l}\text { Discontinue ticlopidine } 14 \text { days before neur- } \\
\text { axial blockade; discontinue clopidogrel } 7 \text { days } \\
\text { before neuraxial blockade }\end{array}$ \\
\hline Platelet glycoprotein IIb/IIIa antagonists & $\begin{array}{l}\text { Contraindicated within } 4 \text { weeks of surgery; } \\
\text { profound effect on platelet aggregation }\end{array}$ & $\begin{array}{l}\text { Avoid neuraxial techniques until platelet } \\
\text { function has recovered; neurologic moni- } \\
\text { toring after postoperative administration } \\
\text { resumes }\end{array}$ \\
\hline
\end{tabular}

DVT = deep vein thrombosis; PE = pulmonary embolism; LMWHs = low-molecular-weight heparins; INR = international normalized ratio; COX-2 = cyclooxygenase- 2 ; NSAIDs = nonsteroidal anti-inflammatory drugs.

Originally published in Ghafoor VL, Epshteyn M, Carlson GH, Terhaar DM, Charry O, Phelps PK. Intrathecal drug therapy for long-term pain management. Am J Health Syst Pharm 2007;64:2447-61.@2007, American Society of Health-System Pharmacists, Inc. All rights reserved. Reprinted with permission. (R0931).

\subsection{Chronic Infection.}

The presence of active infection is typically viewed as a contraindication to placement of all implantable devices (88). Any type of active infection may introduce the risk of bacteremia and seeding of the implanted system, although the actual magnitude is unknown. Patients previously identified as carriers of methicillin-resistant Staphylococcus aureus (MRSA) are known to be at an increased risk for infection. A preoperative nasal swab should be incorporated into the selection process for these patients to confirm that MRSA is not present at the time of surgery (88). Particularly for those patients with noncancer pain, the panel views the presence of any active infection as a relatively strong, although not absolute, contraindication to placement of a permanent IT drug delivery system. Complicated cases may benefit from consultation with an infectious diseases specialist to provide further insight into condition-specific safety concerns (92).

\subsection{Obesity-Related Obstructive Sleep Apnea.}

The prevalence of obesity has reached epidemic proportions, affecting between $33 \%$ and $35 \%$ of US adult men and women, respectively, in 2005 and 2006 (93). Obesity predisposes individuals to developing symptoms of obstructive sleep apnea (OSA) due to profound anatomic changes that produce upper-airway obstruction during normal sleep, causing temporary apneic episodes. Present in more than 18 million US adults (94), OSA can lead to significant sequelae, including chronic carbon dioxide retention and pulmonary hypertension. 
OSA has also been associated with an increased sensitivity to the respiratory-depressant effects of opioids; thus, use of long-term oral opioid therapy may carry an elevated risk of respiratory depression in this patient population (95). An observational study by Webster et al reported that sleep-disordered breathing was present in $75 \%$ of patients treated with chronic opioid therapy, with $39 \%$ of these individuals having OSA ( $n=$ 147) (96). As results from overnight polysomnographies demonstrated, opioids may have contributed to sleeprelated apnea in chronic pain patients in this study (96). However, the researchers emphasized that opioid therapy may still be permissible in individuals with chronic pain provided they are carefully monitored by prescribing physicians (96). Three case reports described by Farney et al also illustrate distinct complications of long-term treatment with sustained-release opioids on respiration by comparing the effects of opioid therapy with common respiratory abnormalities exhibited by opioid-naïve OSA patients (95). Opioid use was associated with increased apnea duration and hypoxia severity during non-rapid eye movement (NREM) sleep, ataxia with irregular respiratory pauses during NREM sleep, and severe hypoxemia (95). Further investigation is needed to explore the extent to which long-term IT opioid therapy may interact with OSA (95).

The American Society of Anesthesiologists recently published updated recommendations to guide the conduct of clinicians in administering neuraxial opioids to potentially high-risk patients, including those at increased risk for respiratory depression (97). Although these guidelines are intended for the management of acute pain, the recommendations may be relevant in the chronic pain setting as well. Horlocker et al advise physicians to obtain a detailed history and perform a physical examination-which should include, but is not limited to, the recording of baseline vital signs, airway, heart, lung, and cognitive function-as part of the patient selection process (97). The panel concluded that continuous IT opioid administration is acceptable in patients with OSA, provided there is adequate monitoring throughout the administration period to minimize the risk of adverse effects (Table 2) (97). Although not documented in the literature, clinical experience has found that many patients on chronic opioid therapy will show improvement when switched from oral to IT opioid delivery. Furthermore, IT therapy may potentially reduce the severity of both OSA and pain, particularly when utilizing combination therapy. Also, the use of IT ziconotide as monotherapy may offer advantages
Table 2. Recommendations for Early Detection of Respiratory Depression Following Opioid Administration (62)

- Patients should be monitored for adequacy of ventilation, oxygenation, and level of consciousness

- Monitoring should take place at least once per hour during the first 12 hours following opioid administration; thereafter, monitoring should occur at minimum once every 2 hours for 12 hours

- 24 hours after administration, monitoring should occur every 4 hours for at least 48 hours

- Increased monitoring is warranted for high-risk patients (eg, those with obesity and/or sleep apnea)

in this setting (98). It is, therefore, permissible for OSA patients to be implanted with a drug delivery device as long as they are carefully evaluated for potential respiratory complications and meet all other criteria for patient selection.

\subsection{Chronic Lung Disease.}

Chronic lung disease manifests in a variety of forms, frequently presenting as reactive airway disease, restrictive pulmonary disease, and chronic obstructive pulmonary disease (COPD). Chronic lung disease currently affects more than 35 million individuals in the United States and causes more than 400,000 deaths annually (99). Of these chronic lung diseases, COPD patients typically experience significant retention of carbon dioxide and are more prone to respiratory depression and respiratory arrest with the administration of systemic opioids than the general population (100). A retrospective case-controlled analysis by Taylor et al found that patients with COPD are most at risk for a respiratory event when administered opioids following surgery (odds ratio 5.09; 95\% confidence interval) (100), as compared with patients without chronic lung disease. Extrapolating to the use of IT opioids, it is reasonable to presume that COPD patients will also have a greater tendency toward respiratory depression when administered opioids via an implantable device.

Although the long-term risk of IT therapy in chronic lung disease patients is unknown, it is likely that patients with COPD may be safely treated with IT opioids, if dosed cautiously. Alternatively, this patient population may benefit from nonopioid IT agents and/or combination therapy, which represent a safer option than oral opioid administration with regard to the risk of re- 
spiratory depression. Thus, the panel recommends close monitoring in patients with chronic lung disease during any IT trial and immediate post-implantation of a permanent system, particularly within the 24 hours following surgery. Evidence has shown that most respiratory events secondary to opioid administration occur within 24 hours post-surgery; more than half occur within less than 12 hours (100). Again, IT ziconotide as monotherapy may offer advantages in this setting (98).

\subsection{Cardiac Disease.}

Limited data support the notion that cardiac abnormalities may independently alter the risk of IT therapy when the $\mathrm{N}$-type calcium channel antagonist ziconotide is used, and the potential for dose-related cardiovascular adverse events may also exist (54). In a randomized controlled safety and efficacy study of IT ziconotide, investigators noted that cardiovascular adverse effects-namely, postural hypotension and hypotension-occurred more frequently in patients in the active treatment group, as compared with those in the placebo cohort (33.3\% vs $10 \%$, respectively) (54). Notably, 32.3\% of postural hypotension events occurred at doses greater than $0.1 \mu \mathrm{g} / \mathrm{hour}$ versus $17.1 \%$ transpiring at doses less than or equal to $0.1 \mu \mathrm{g} / \mathrm{hour}$ (19). The researchers concluded that in addition to initiating treatment at lower dosages, using smaller dose increments and increasing the time between dose titrations reduced the frequency of adverse effects (54).

Since there are no specific guidelines detailing the impact of cardiac abnormalities on IT therapy, the panel recommends that all candidates with a history of cardiovascular disease be evaluated for the implantation of an IT drug device system via the risk stratification guidelines outlined by the American College of Cardiology (ACC)/ American Heart Association (AHA) (101). Similarly, the possibility of perioperative morbidity or mortality should also be assessed for patients 50 years of age or older, due to the prevalence of cardiac risk factors in this population (101). An evaluation that reveals 1 or more major clinical risk factors (ie, unstable coronary syndromes, decompressed heart failure, significant arrhythmias, or severe valvular disease) may require surgery to be postponed or cancelled to allow for proper management of the condition. Although it is permissible to proceed with implantation in patients with a history of ischemic heart disease, compensated or prior heart failure, or cerebrovascular disease, extreme caution should be exercised when operating on individuals with these intermediatelevel risk factors (101).

\subsection{Kidney Disease.}

Approximately $12 \%$ of US adults, or 23 million individuals, suffer from chronic kidney disease (CKD), with over half a million adults being treated for endstage renal disease (102). There is little available data, but the presence of CKD-including end-stage renal disease requiring hemodialysis-does not appear to impact the efficacy or safety of IT therapy. However, patients with CKD have a higher incidence of cardiac disease compared with the general population (103). It is, therefore, recommended that clinicians consider the risk/benefit ratio outlined by the ACC/AHA prior to proceeding with device implantation. Patients with a preoperative creatinine level greater than $2 \mathrm{mg} / \mathrm{dL}$ are at an increased cardiac risk after surgery and require escalated surveillance before the decision to proceed with IT delivery can be made (101). For CKD patients deemed appropriate for surgery, clinicians should also be aware of challenges associated with finding a comfortable location for the placement of an indwelling pump in individuals receiving peritoneal dialysis. Haematuria-loin pain syndrome is now believed to be a renal version of complex regional pain syndrome (CRPS). Such patients have severe neuropathic pain in the loin or pelvis area if an attempt has been made to "denervate" the kidney and transposition into the pelvis. IT drug therapy may be appropriate, despite the presence of CKD.

\subsection{Geriatric Issues.}

The incidence of chronic pain in the geriatric population is substantial, and the elderly are thought to account for approximately $25 \%$ of all chronic pain patients annually (104). The percentage of elderly individuals with chronic pain may actually be significantly higher; it is believed that pain severity is often underreported in older populations, resulting in the tendency to undertreat elderly patients (104). Specifically, the practice of underprescribing opioids to older individuals is all too common and results in poor pain management (104).

Clinical experience and empiric evidence have suggested an age-dependent effect with the use of chronic opioid administration, such that older patients are often more responsive and less likely to develop a tolerance to opioid therapy (105). It is important to note, however, that the use of opioids in the geriatric population is complicated by the escalating tendency for the development of comorbidities and the necessity for polypharmacy; as patients age, they are more likely to present with any number of conditions, including those previously described in this section $(76,77)$. 
Since many elderly patients will also have some degree of organ dysfunction as a result of their advanced age, clinicians must be cognizant of how this physiologic decline will affect the onset of action, rate of elimination, and half-life of administered drugs (104). The use of opioid therapy in the elderly is further confounded by the increased likelihood for cognitive impairment. Since opioids are also known to cause thought process disturbances, it can be difficult to determine the cause of dementia in older patients treated with these agents (104). In addition, elderly patients suffering from cognitive impairments may have difficulty communicating their pain experience or the development of adverse effects, which can lead to poor outcomes as a result of undertreatment/overtreatment (104). Other problems, such as dizziness and respiratory depression, which are often associated with opioid therapy, may be more problematic in geriatric patients, many of whom are already at an increased risk for falls and fractures (104).

Although the panel does not recognize advanced age as an absolute contraindication, elderly patients must be thoroughly evaluated for preexisting medical comorbidities before they can be considered for IT therapy. Any condition that is identified should be evaluated according to established protocols and practice recommendations prior to implanting a drug delivery system. The use of IT opioids is permissible in geriatric patients provided the prescriber remains vigilant for potential adverse effects of therapy; alternatively, the panel recommends the use of nonopioid IT therapy as a viable substitute to opioid administration.

\subsection{Addiction.}

Opioid use disorders include misuse, abuse, and addiction. Loss of control is a hallmark of addiction; it is also a behavior observed in some individuals who abuse their medications in an effort to relieve uncontrolled pain or comorbid mental health disorders. It is estimated that $20 \%$ to $40 \%$ of patients with pain will abuse their medications or manifest the disease of addiction (106). Many of these patients are not seeking a high, but simply have difficulty controlling the consumption of their medications as prescribed. Uncontrolled pain can be a tremendous motivator for noncompliance. Patients may overuse their medications in an attempt to escape pain, yet discover in the process that more medication still fails to achieve the desired effects. In such cases, overuse of medication can lead to dangerous behaviors or even overdose and death. Importantly, the panel believes that some addicted patients may be reasonable candidates for IT therapy. Eliminating oral opioids and using only IT opioids shifts the control of medication administration from the patient to the pump as prescribed by the physician; nonopioid IT therapy is also a reasonable option for patients with serious abuse problems or the disease of addiction.

Although potentially beneficial, the use of IT therapy in the treatment of the addicted patient is not without its problems, and it should be carried out with caution and in conjunction with an addictionologist. The incidence of personality disorders in the addicted population is significant; such patients can be demanding, manipulative, passive-aggressive, and generally noncompliant (107). When treating a crossaddicted patient, there is no assurance that the patient will not turn to alcohol, illicit drugs, benzodiazepines, or the like following resolution of the pain problem. Although rare, patients have also been known to penetrate the pump or catheter to gain access to the drug. Burton et al (108) reported a case of self-administration of phencyclidine, methamphetamine and propoxyphene into an intrathecal pump by an incarcerated patient. One of the panel members recalls treating an anesthesiologist who had an undiagnosed addiction to fentanyl. The patient was discovered to be accessing his pump-which had been implanted for the treatment of what appeared to be a legitimate pain problem associated with concordant pathology-with relative ease. In another case, a patient attempted to "cut the pump out" in an effort to extract the drug. It is also important to be vigilant to the situation where the patient is the "mule" and provides the means for others to secure drugs for use or sale. One must never underestimate the ingenuity and persistence of some addicts.

\subsection{Panel Recommendations.}

IT drug delivery offers therapeutic advantages to patients with a variety of painful disorders and advanced medical illnesses that affect a wide range of organ systems. The panel does not recognize any preexisting medical comorbidity as an absolute contraindication for IT therapy. When evidence from the established literature is not available to guide the patient selection process, clinicians should abide by published guidelines and practice recommendations for the existing comorbidity and use clinical judgment to ascertain the appropriateness of proceeding with device implantation. 


\subsection{Associated Psychological Considerations}

Psychological factors intermingle with physical characteristics to influence the experience of pain through behavioral/environmental, cognitive/affective, and neurochemical/physiological mechanisms. This interplay of multidisciplinary issues supports the relevance of a tailored psychological assessment as part of the patient selection process for IT therapy.

A psychological consult in the pain management setting entails the identification of relevant psychological factors and their potential impact on long-term outcomes. Areas of concern may include the patient's ability 1) to be educated as to expectations for, and benefit of, the treatment modality; 2 ) to prepare for, commit to, and subjectively assess long-term therapeutic impact; and 3) to participate in, and gain benefit from, concomitant behavioral or cognitive therapy designed to improve functional activities and maximize quality of life (109). Attention to potentially modifiable psychological states, such as depression and anxiety, which can exacerbate the experience of pain and impair the ability of the patient to cope effectively, is essential. Importantly, the role and impact of the psychosocial factors is often dynamic and can fluctuate in relation to time and clinical or personal circumstances. Changes in mood and psychosocial status-including depression, divorce, and interpersonal conflicts-can also emerge as unanticipated psychosocial complications (110).

\subsection{Psychological Variables as Predictors of Outcomes}

Psychological conditions-such as suicidal depression, schizophrenia with active psychotic behavior, and active drug abuse-are routinely considered as contraindications for implantable pain therapies (111). In a systematic review of the literature relating to pretreatment psychological variables as predictors of outcome, Celestin et al identified a positive relationship between 1 or more psychological factors and poor treatment outcomes in $92 \%$ of the 25 studies they reviewed (112). Presurgical somatization, depression, anxiety, and poor coping tended to be predictive of a poor response to treatment. Although these data suggest a possible correlation between psychological status and the effect of pain-related treatment, current empiric research has yet to reveal a specific set of variables associated with positive or negative outcomes. For example, contrary to what might be expected, a study by Doleys and Brown demonstrated that patients with mildly abnormal Minnesota Multiphasic Personality Inventory-2 (MMPI) personality profiles reported a higher percentage of improvement in pain after 4 years of IT therapy compared with patients with a more "normal" MMPI (113). Thus, patients should not be excluded based solely on such findings without first considering other aspects of the psychological evaluation. Furthermore, presuming the existence of "predictors" assumes a standard set of outcomes or goals for all patients, when in fact, the goals are likely to vary for cancer versus noncancer pain and for pain versus spasticity. Likewise, the treatment approach may vary based on the specific condition (eg, severe CRPS type I or II vs failed back surgery syndrome or multilevel degenerative disc disease). To date, it also appears more likely that one will identify characteristics associated with "poor outcomes" than with "good outcomes" $(112,114)$.

Although a detailed psychological assessment may have limited prognostic value, the evaluation process can be used to facilitate the initiation of appropriate individualized treatment to properly prepare the patient for implantation and long-term treatment (109). Targeted psychological/behavioral interventions can often mitigate the impact of aberrant psychological issues (ie, excessive reinforcement for maladaptive pain behaviors) and create a patient with a more favorable prognosis.

\subsection{Strategies for the Psychological Evaluation}

With an estimated $75 \%$ of chronic pain patients identified as having relevant psychological factors (115), a focused pretrial psychological consult is often beneficial. The primary goal of assessment-which usually includes a 1-hour clinical interview-is to develop a functional patient description that offers context for the pain behavior. Communication should transpire between the healthcare team, patient, and support person. At least 2 studies have documented that significant others tend to perceive outcomes of IT therapy differently than patients $(116,117)$, and incorporating others involved with the patient's care into the assessment can offer an alternative perspective from which to consider the patient-provided information. The more vague or ambiguous the patient is, the greater the need to identify appropriate and measurable functional goals and consider a functionally oriented trial $(118,119)$.

According to Williams and Epstein, psychological factors most routinely assessed during a consult consist 
of psychiatric disorders, such as axis II or personality disorders; depression; substance abuse; secondary gain, including litigation and workers' compensation; and motivation for receiving an implantable device (120). Assessing the impact of mood disorders has received more attention than the role of personality disorders. The latter tend to be uncovered by the patient's history, via the clinical interview, psychological testing, or over time in the course of the doctor-patient relationship. The manner in which patients with personality disorders-such as the hysterical, dependent, and borderline-interact with the practitioner and office personnel can be very unsettling. Their predisposition toward manipulation and their demand for attention and control can complicate every phase of treatment (107).

Issues of cognitive functioning gain relevance as those who are cognitively impaired (eg, through dementia, traumatic brain injury, Alzheimer's disease) may have difficulty identifying and communicating changes in pain and may respond in a different manner to IT therapy than patients who are not cognitively impaired (115). Additional challenges associated with cognitive dysfunction-including difficulty with comprehending goals, expectations, and rationale for IT therapy-might require supplementary education or closer involvement of a support person (115).

\subsection{Related Influences on the Psychological Assessment}

Patient beliefs and coping strategies may shape positive or negative therapeutic outcomes by revealing the level of vulnerability to external influences on pain management. Viewpoints related to more favorable results include 1) patient understanding of pain as a multifactorial experience that can be affected by the patient's own attitudes and behaviors; 2) belief in the effectiveness of exercising coping skills and acceptance; and 3 ) active involvement in treatment-related decisions (110). In contrast, individuals who tend to restrict the pain experience to its physical characteristics or medical cause and minimize the role of psychosocial factors are more likely to experience negative outcomes (110).

Despite the value of measurable psychological characteristics, clinical scenarios can exist in which the severity of physiologic symptoms may take precedence over psychological concerns. The demands of certain conditions-such as a patient with CRPS manifesting a very dystrophic, swollen, and hyperalgetic extremitymay require a deviation from the widespread practice of advancing from conservative to invasive pain man- agement (121). Notably, it is also important to remain vigilant over those patients lacking any significant maladaptive or pathological psychological conditions, as the future can be very unpredictable. Brief, but regular, post-implant office visits for the purpose of reinforcing and supporting positive changes may pay big dividends.

\subsection{Panel Recommendations}

The panel recommends a pretrial or preimplantation psychological consultation for patients with chronic noncancer pain being considered for IT therapy. However, the inability to have a specialist conduct the psychological consult-whether due to geographic location and/or resource limitations-is not an absolute contraindication to device implantation. In such cases, it will behoove the physician to become acquainted with the relevant psychosocial issues and integrate these as much as possible into the evaluation and treatment of the patient. The evaluation should highlight characteristics that may positively or negatively impact a trial or long-term therapy. The potential influence of identified psychological factors should be outlined to the patient and significant other. Patients manifesting 1 or more of the characteristics listed in "Contraindications for Immediate Trial//mplant" of Table 3 should be considered with great caution; individuals exhibiting attributes outlined in "Indications to Proceed With Trial/Implant" could be viewed as more appropriate candidates from a psychological perspective. The psychological evaluation should also assess the need for any pretrial, preimplantation, or postimplantation targeted psychological/ behavioral interventions determined to be potentially beneficial in obtaining or sustaining a positive outcome. A multidisciplinary approach to patient selection should be undertaken wherever possible to account for the multifactorial nature of pain and to avoid isolation of the psychological components. The psychological consultant should have some level of participation in the preimplant trial and/or follow-up to evaluate the utility of the assessment and help determine whether the therapeutic goals have been achieved.

\subsection{Social IsSues}

Although none are likely to represent an absolute contraindication to IT therapy, a number of social issues may be influential in the patient selection process. $\mathrm{Pa}$ tient demographics, activity level, insurance coverage, compliance issues, and the potential for opioid abuse are all likely to impact treatment outcomes. 
Table 3. Psychological Factors Influencing Patient Selection*

\begin{tabular}{|c|c|}
\hline Contraindications for Immediate Trial/Implant & Indications to Proceed With Trial/Implant \\
\hline $\begin{array}{l}\text { - Untreated significant addiction } \\
\text { - Active psychosis with delusional/hallucinatory } \\
\text { components } \\
\text { - Major uncontrolled depression/anxiety } \\
\text { - Active suicidal or homicidal behavior } \\
\text { - Serious cognitive deficits } \\
\text { - Severe sleep disturbances }\end{array}$ & $\begin{array}{l}\text { - Generally stable psychologically } \\
\text { - Cautious } \\
\text { - Effectively defensive } \\
\text { - Moderate levels of self-confidence and self-efficacy } \\
\text { - Realistic concern regarding "illness" and proposed therapy } \\
\text { - Mild depression appropriate to the situation } \\
\text { - Generally optimistic regarding outcome } \\
\text { - Ability to cope with flare-ups, complications, and side effects appropriately } \\
\text { - Appropriately educated regarding procedure and device } \\
\text { - Supportive and educated family/support person } \\
\text { - History of compliance and cooperativeness with previous treatment } \\
\text { - Behavioral/psychological evaluation consistent with patient's complaints and } \\
\text { reported psychosocial status } \\
\text { - Comprehends instruction(s) and other information } \\
\text { - Patient/significant other has appropriate expectation(s) } \\
\text { - Patient able/willing to "tolerate" medication adjustments with drug delivery } \\
\text { system }\end{array}$ \\
\hline
\end{tabular}

${ }^{*}$ Based on experience and conjecture; not clinically or experimentally validated $(74,79)$.

\subsection{Healthcare Coverage and Patient Compliance Factors.}

The majority of commercial health insurers-as well as Medicare/Medicaid and workers' compensation programs-provide coverage for the IT modality when utilized for approved indications, as intraspinal analgesia is a FDA-approved, commercially available treatment for intractable chronic pain. Since prior authorization for treatment will likely be required, it is necessary to confirm that a patient's coverage provides for both surgical implantation and ongoing medication refills prior to initiating IT therapy. A survey of 87 pain practitioners indicated that only $25 \%$ were satisfied with the reimbursement received from private insurance companies and approximately $35 \%$ were satisfied with reimbursement received from workers' compensation plans; the vast majority $(90.5 \%)$ believed that reimbursement for filling, refilling, and programming medication pumps was insuf- ficient to cover practice costs (72). Thus, the patient's out-of-pocket expenses associated with treatment will vary by plan and may be significant. The patient's willingness and ability to cover these expenses may influence which individuals are suitable candidates for treatment.

The capacity of the patient to comply with the medication refill schedule is also a crucial component of the IT therapy selection process. Initially, pump refills and dose adjustments are required approximately every 8 weeks; however, over time patients who develop a tolerance to therapy may require refills more frequently, possibly as often as every 4 to 6 weeks (74). Only patients who are willing and able to maintain their refill schedule-typically those who do not have cognitive, psychological, or socioeconomic barriers and who benefit from family support-should be selected for treatment. 


\subsection{Panel Recommendation.}

Published research to date does not confirm a direct link between social factors and outcomes of IT therapy, and therefore, consideration of these factors should not definitively support or contraindicate treatment. Nevertheless, certain considerations may provide insight into the potential effect and/or consequences of treatment; these associated social issues should be carefully weighed during the patient selection process.

\subsection{Prior Therapy and Its Results}

Pain management strategies are individually tailored based on comprehensive evaluation of overall health status and pain-related history (122). The pain treatment continuum for chronic noncancer pain begins with conservative options, such as exercise programs, meditation and relaxation techniques, and overthe-counter pain medications $(1,39)$. Subsequent steps include adjuvant medications for treating neuropathic pain, physical rehabilitation, somatic and sympathetic neural blockade for specific pain conditions, cognitive and behavioral therapies, and/or oral or other systemic opioid medications $(10,11,74)$. More aggressive options are reserved for the small fraction of patients who do not improve with more conservative measures and include spinal cord stimulation, spinal (IT) drug delivery, and/or neurodestructive procedures $(10,11,74)$. Patient selection criteria for IT drug delivery system implantation-namely exhaustion of all attempts at treatment of the underlying disorder responsible for the ongoing pain, failure of less invasive therapies, and inadequate effect or intolerable adverse effects with use of oral opioids-reflect this step-wise therapeutic approach (74). IT drug delivery in noncancer-related pain has been studied in a limited number of controlled trials $(54,123$ 125) - many of which focus on the use of ziconotide or ziconotide-morphine combination therapy-although numerous observational studies suggest that IT drug delivery with a variety of agents provides significant pain reduction in certain patients whose chronic pain fails to respond to more conservative management $(56,126)$.

Opioids can provide effective analgesia via many routes of administration-oral, transdermal, and intravenous or neuraxial routes (epidural and IT)-and the simplest effective route should be employed. Yet, chronic opioid therapy in the long-term management of noncancer-related pain remains controversial (127129). Advocates point to long-term efficacy and improvement in function in patients with chronic pain- ful conditions, including low back pain (47), whereas opponents cite difficulties in prescribing these drugs over extended periods of time (130). The traditional paradigm for opioid treatment is based on cancer pain management (130). In this approach, patients with significant chronic pain are given a long-acting opioid for continuous analgesia, as short-acting opioids may cause fluctuations in pain control.

Nearly every available opioid has been used successfully in treating chronic low back pain, including shortacting agents (eg, hydrocodone, oxycodone), alone or in combination with ibuprofen or acetaminophen, and long-acting agents (eg, methadone, transdermal fentanyl, controlled-release oxycodone) (131-133). Oral or transdermal opioids are the most commonly used agents, and an estimated $80 \%$ to $90 \%$ of patients with chronic noncancer pain attain adequate pain control with these therapies $(10,11,65)$. However, there remains a small, but significant, percentage of chronic pain patients who do not achieve effective pain relief with traditional regimens.

Intolerable adverse effects-another common drawback of systemic opioids-are more likely to occur at higher dosages, and therefore, can be problematic for patients requiring dose escalation to achieve adequate pain control. Commonly reported adverse effects include gastrointestinal distress (eg, nausea, vomiting, constipation, diarrhea) (117); impaired cognition (eg, memory lapses, confusion) (117); urinary retention or incontinence (117); pruritus (75); interference with the touch sensation (74); impaired motor function and sympathetic reflexes (74); and central nervous system (CNS) conditions, such as drowsiness or cloudiness (74). Clinical experience suggests that higher opioid doses may also produce a greater-than-normal sensitivity to pain, possibly as a result of increased stimulation of the CNS that does not occur with lower opioid dosages (75).

There are no studies that directly address the correlation between response to systemic opioids and subsequent response to IT therapy for the management of noncancer pain. Clinical experience and extrapolation from the extensive experience with treatment of cancer pain suggests successful pain relief can be achieved in patients with a previous history of poor pain relief or adverse reactions with systemic opioids $(15,134)$. Greater efficacy with IT therapy as compared with systemic treatment may stem from the direct application of agents close to their site of action at the spinal dorsal horn $(135,136)$. IT administration also allows for a variety of medications to be administered as monotherapy, 
including nonopioid formulations, or in various admixtures; if morphine is ineffective or has intolerable adverse effects, the physician may attempt a course of another opioid (eg, hydromorphone, fentanyl, or sufentanyl) or a "cocktail" combining agents from different drug classes (eg, an opioid plus bupivicaine) (15).

\subsection{Panel Recommendation.}

For patients with chronic noncancer pain, a stepwise approach to therapy in which treatment begins with the least aggressive approach and progresses only when therapy fails to safely provide adequate analgesia is recommended. Most often the advancement to IT therapy is warranted when more conservative treatment options have failed; however, a more aggressive approach may also be necessary in patients with difficulty managing their medications or for individuals with certain comorbid conditions (eg, morbid obesity or sleep apnea) for whom the use of oral opioids has the potential for detrimental adverse effects.

A direct correlation between response to systemic opioids and subsequent response to IT therapy has not been clearly established; nonetheless, uncontrolled trials and clinical experience suggest that patients who achieve a $50 \%$ or greater reduction in pain with systemic opioids are likely to achieve a therapeutic benefit with IT therapy $(10,11)$, accompanied by a lower rate of adverse effects. The spinal dorsal horn is rich in receptors and ion channels that modulate pain. It is reasonable to assume that combination spinal drug delivery is likely more effective than systemic analgesic therapy; however, there is no literature to support this. In addition, there is no literature to support the predictive value of response to systemic nonopioids when administered spinally.

\subsection{Spinal and Anatomical technical FACTORS}

Safe and efficient access to the anatomical region of the spine is an indispensable procedural element of IT drug delivery device implantation and outcome management (137). However, recommended catheter insertion at the L2-3 or L3-4 level can be complicated by unique patient profiles and histories (138); disease pathology, inherited or acquired medical characteristics, and associated anatomic variations in the spine require perioperative consideration to optimize surgical technique and device placement (137). Metastatic involvement or occult pathology in the spinal column (88), arthritis in the joints, paraplegia, spasticity, and scoliosis may impose restrictions on ideal patient positioning for the procedure, thereby requiring the determination of an alternate position to avoid compromising sterility and patient safety (137). Fluoroscopy should be used in a compensatory effort to correct any residual anatomic tilt (137). Anatomic variation may also impede recommended redirection of the catheter to the IT space for the final tip position (137). Furthermore, abnormal anatomy may obscure recognition of the pressure gradient between the epidural space and the spinal fluid (137).

Arterial blood supply, CSF bulk flow, and diffusion through the dura and meninges characterize anatomic factors that could influence therapeutic outcomes through the uptake and delivery of IT agents (137). At this time, no firm recommendations can be made on optimum catheter tip location. However, if there is poor CSF return at the time of placement, consideration should be given to perform a radionucleotide study (Indium) to assess CSF distribution. Previously described disparities in nerve root size and volume also impact response to IT agents (137).

The panel recognizes the influence of a wide array of spinal and anatomic considerations on the patient selection process and encourages comprehensive review of physical attributes to ensure preimplantation identification of potential technical challenges.

\subsection{Technical Factors: Device-Related LIMITATIONS}

There are a number of technical concerns that must be considered when selecting a patient for treatment using IT drug therapy. Most notable is the size of the IT pump and the subcutaneous position and route that the tunneled catheter will take during surgical placement. Before the procedure, the patient must clearly understand the size and location of the proposed pocket for the IT pump. Most devices are large, and the only region suitable for placement is the left- or right-lower quadrant of the abdomen (88). However, in patients with an overhanging panniculus, higher placement may be necessary. It is important to mark the pump location while the patient is in the sitting position for optimum placement. Special care must be taken to avoid proximity to the anterior rib or iliac crest, which can cause painful contact of the pump with the structures, even after complete healing of the surgical incisions (88). Placement can be complicated by extensive scarring caused by prior abdominal surgery. The presence of a colostomy or other enterocutaneous ostomy must 
be carefully considered when selecting the position for creation of the pump pocket. The presence of ongoing infection or significant skin breakdown anywhere along the course of the proposed position for the tunneled catheter is a relatively strong contraindication to placement (83). Minor variations in the depth of the implant site are appropriate based on weight ranges, with special consideration to maintain pump accessibility for required refills (88); the pump may be implanted within the mid-fat plane of the lower quadrant of the abdomen or directly over the anterior fascia of the rectus abdominis muscle to accommodate for variation in body habitus of individual patients (88). It is necessary to secure the pump with suture to prevent rotation. Fascia is the optimum tissue for securing the pump; however, if the pump is placed in the mid-fat plane, it can be sutured to the fat, as scar tissue will form rapidly around the sutures and pump, securing the device in place.

The use of IT drug therapy is technically challenging and relies on an understanding of the pharmacology of IT opioids and proper use of the infusion device. The role of the individual practitioner is critical in ensuring safe use of IT opioid therapy. A recent large-scale epidemiology study has established that there is excess mortality associated with the use of IT opioid therapy for the treatment of noncancer pain (139). Every practitioner using IT therapy must understand that there is risk of fatality, particularly soon after implantation. In the absence of data to guide practice, we must adopt a commonsense approach. It seems logical that practi- tioners can minimize their contribution to this risk by considering the factors outlined in Table 4 (66). A working knowledge of possible device malfunctions is also crucial for clinicians to anticipate potential mechanical failures, many of which can result in serious adverse effects (Table 5) (140).

\subsection{Economic Factors}

Pain affects a staggering number of individuals in the United States each year. An estimated 76.5 million adults 20 years of age or older report having experienced pain that lasted more than 24 hours, a number that exceeds the combined incidence of diabetes, coronary heart disease, stroke, and cancer (141). Approximately $15 \%$ to $25 \%$ of adults report having chronic pain-commonly defined as pain that persists for 6 months or longer-at any given time; in patients older than 65 years of age, the prevalence escalates to $50 \%$ $(10,11,142)$. The economic consequences of chronic pain are also substantial, amounting to an estimated $\$ 100$ billion annually in direct and indirect costs (141). Although the clinical and economic effects of intractable pain undoubtedly warrant proper treatment, the most appropriate and cost-effective method of therapy is often less clear. Systemic opioid administration is preferred over more invasive intraspinal modalities (74), since oral and intravenous opioid regimens are not associated with surgery-related adverse effects (eg, postoperative infection, wound infection, meningitis, and postdural puncture headache) and allow for a lower

Table 4. A "Commonsense Approach" to minimizing the risk of mechanical failure and adverse effects with it therapy.

1. Initiate IT therapy with a safe starting dose, even if the dosage is insufficient to provide effective pain relief

2. Avoid use of concomitant CNS depressants in the immediate post-implantation period

3. Gain an expert understanding of the IT drug pump, its construction, and proper programming

4. Personally oversee all aspects of the initial programming

5. Avoid use of excessively concentrated solutions during initiation of therapy to minimize the delay in onset of drug effects associated with slow infusion rates

6. Routinely calculate when new drug will first enter the IT space and warn the patient and their caregivers to be most vigilant during this interval of time

7. Avoid the use of conversion tables to determine the initial starting dose, as doses that are calculated at equal analgesic amounts from standard conversion tables have no support in the literature and may be lethal

$\mathrm{IT}=$ intrathecal; $\mathrm{CNS}=$ central nervous system.

Adapted from Falco et al (31). Systematic review of diagnostic utility and therapeutic effectiveness of cervical facet joint interventions. Pain Physician 2009; 12:323-344. 
Table 5. Summary of Potential Pump Failures.

- Catheter pump misconnection

o May occur in the immediate postoperative period, but can also be delayed in onset

- Loss of pump propellant

o Can manifest as an excessive or reduced drug delivery rate

o Results in a range of symptoms, from overdose to acute withdrawal adverse effects

- Gear shaft wear and motor stall

o Leads to symptoms of drug underinfusion, not always accompanied by an alarm

- Leakage of infused drug

o May occur at the catheter-pump connection in either the immediate postoperative period or with some delay

o Can be caused by a needle piercing the catheter wall; infiltration of an additional local anesthetic utilized when closing the incision site; trauma to the catheter by self-retaining or hand-held "cat's paw" retractors; or kinking of catheter in close proximity to the pump

- Displacement of IT catheter

o May result in a local hygroma caused by CSF leakage

- Kinking of IT catheter

o Can occur anywhere from the pump to the catheter receiving device alongside the spine

o Complicates and/or prevents attempts to aspirate CSF or inject via the pump side

- Obstruction by IT catheter tip fibroma or fibrous sheath

o May be related to increasing doses/concentrations of opioids

o Associated with decreased analgesic effect, new back pain, withdrawal symptoms, and/or potential for neurologic adverse effects

IT $=$ intrathecal; $\mathrm{CSF}=$ cerebrospinal fluid.

Adapted from Pergolizzi et al (104). Opioids and the management of chronic severe pain in the elderly: consensus statement of an international expert panel with focus on the six clinically most often used World Health Organization step III opioids (buprenorphine, fentanyl, hydromorphine, methadone, morphine, oxycodone). Pain Pract 2008;8:287-313.

initial expenditure (74). Yet, for patients who require a more aggressive approach to therapy, implantable drug delivery systems may provide a cost savings when used to maintain long-term analgesia.

Economic factors greatly influence treatment choices and can potentially prevent the implementation of effective therapy. According to a 2009 survey of healthcare practitioners who actively utilize implantable drug devices, $40.5 \%$ of respondents identified the cost of pump implantation as the greatest economic barrier to providing IT therapy (72). Drug and refill fees were also an important deciding factor, considered to be the greatest deterrent to IT delivery by $34.5 \%$ and $25 \%$ of respondents, respectively (72). In fact, $87.2 \%$ of those surveyed believed the cost of IT agents to be at least somewhat important during the patient selection process (72). Other economic considerations may also interfere with patient access to therapy, including issues related to reimbursement and out-of-pocket expenses (72).

Several analyses have been performed to determine the cost of treatment with an implantable de- vice, as compared with more conservative therapeutic approaches; however, these studies date back 10 to 20 years, and thus the data are not contemporary. Nonetheless, there is limited evidence suggesting that IT therapy is a cost-effective option (143-145). Using patient hospital financial service records and homecare vendor quotations, an early analysis by Bedder et al of 20 chronic pain patients determined the total 6-month cost of utilizing an exteriorized system to be roughly $\$ 22,000$ compared with an approximate total cost of $\$ 18,000$ for drug delivery via an implantable device (143). Although cost of treatment at 3 months was similar for both systems, researchers reported that the cost benefits accrued to the implantable device during longterm therapy (up to 12 months) (143). A 1997 analysis by de Lissovoy et al of a large simulated cohort of patients with failed back surgery syndrome $(N=1000)$ evaluated the cost-effectiveness of IT therapy compared with alternative medical management over the course of 36 to 60 months (144). Factoring in expenses associated with managing adverse effects and the price of pump replacement due to battery depletion or mechanical fail- 
ure, the cost of IT therapy through a 60-month period was found to be lower than standard medical management ( $\$ 82,893$ vs $\$ 85,186$, respectively) (144). Researchers reported a similar cost savings in patients utilizing IT therapy for up to 5 years (145).

In the absence of more recent cost analyses, the following example has been developed to provide a more current look at cost issues relating to IT therapy. This model examines the cost of providing analgesia with high- or low-end IT monotherapy-as compared with a brand name or generic oral regimen-assuming that all regimens provide equal efficacy. Based on the cost of monotherapy, Prialt $\circledast$ was selected as the high-end IT treatment and morphine was chosen as the low-end IT therapy. Clearly, patients often require combination therapy to achieve analgesia and many physicians now use IT admixtures in clinical practice; in relation to this model, the cost of most combination therapies will fall between that of Prialt $\circledast$ monotherapy and morphine monotherapy. Table 6 outlines the average cost per month for therapy with IT Prialt $₫$, IT morphine, an oral brand name drug regimen, and an oral generic drug

Table 6. Cost comparison of a high-end and a low-end it medication versus a brand name oral drug regimen and generic drug regimen (months).*

\begin{tabular}{|c|c|c|c|c|c|}
\hline $\begin{array}{c}\text { Drug Regimen and } \\
\text { Dose }\end{array}$ & $\begin{array}{c}\text { Time } \\
\text { (months/30 } \\
\text { days) }\end{array}$ & $\begin{array}{l}\text { Average } \\
\text { Cost }(\$)\end{array}$ & $\begin{array}{c}\text { Drug Regimen and } \\
\text { Dose }\end{array}$ & $\begin{array}{c}\text { Time } \\
\text { (months/30 } \\
\text { days) }\end{array}$ & $\begin{array}{l}\text { Average } \\
\text { Cost }(\$)\end{array}$ \\
\hline IT Prialt ${ }^{\circ}$ & 0 & 0 & Oral Brand Name Regimen & 0 & 0 \\
\hline \multirow{5}{*}{$\begin{array}{l}\text { Average dose } 4 \mathrm{mcg} / \text { day } \\
\text { in } 20 \text {-mL Medtronics } \\
\text { pump }\end{array}$} & 1 & 781.20 & \multirow{12}{*}{$\begin{array}{l}\text { OxyContin } 80 \mathrm{mg} \text { TID } \\
\text { Percocet }{ }^{\star} 10 / 325 \mathrm{mg} \\
8 \mathrm{x} \text { day } \\
\text { Lyrica }^{\circledR} 150 \mathrm{mg} \text { BID } \\
\text { Cymbalta }^{\circ} 60 \mathrm{mg} \text { QD } \\
\text { Klonopin }^{\circ} 1 \mathrm{mg} \text { BID } \\
\text { Ambien }{ }^{\circledR} \text { CR } 12.5 \mathrm{mg} \\
\text { QHS }\end{array}$} & 1 & 2856.00 \\
\hline & 2 & 1562.40 & & 2 & 5712.00 \\
\hline & 3 & 2343.60 & & 3 & 8568.00 \\
\hline & 4 & 3124.80 & & 4 & $11,424.00$ \\
\hline & 5 & 3906.00 & & 5 & $14,280.00$ \\
\hline \multirow{7}{*}{$\begin{array}{l}\text { Medicare J2278 unit } \\
\text { measure billing per } 1 \\
\text { mcg } \\
\text { ASP }+6 \%=\$ 6.51 / \mathrm{mcg}\end{array}$} & 6 & 4687.20 & & 6 & $17,136.00$ \\
\hline & 7 & 5468.40 & & 7 & $19,992.00$ \\
\hline & 8 & 6249.60 & & 8 & $22,848.00$ \\
\hline & 9 & 7030.80 & & 9 & $25,704.00$ \\
\hline & 10 & 7812.00 & & 10 & $28,560.00$ \\
\hline & 11 & 8593.20 & & 11 & $31,416.00$ \\
\hline & 12 & 9374.40 & & 12 & $34,272.00$ \\
\hline IT Morphine & 0 & 0 & Oral Generic Regimen & 0 & 0 \\
\hline \multirow{6}{*}{$\begin{array}{l}\text { Average dose } 6 \mathrm{mg} / \text { day } \\
\text { in Medtronics } 20-\mathrm{mL} \\
\text { pump }\end{array}$} & 1 & 50.94 & \multirow{12}{*}{$\begin{array}{l}\text { Methadone }^{\star} 10 \mathrm{mg} \text { QID } \\
\text { Oxycodone }^{\star} 15 \mathrm{mg} \text { QID } \\
\text { Gabapentin } 400 \mathrm{mg} \\
\text { QID } \\
\text { Desipramine } 10 \mathrm{mg} \text { TID } \\
\text { Trazodone }^{\star} 50 \mathrm{mg} \text { QHS }\end{array}$} & 1 & 318.00 \\
\hline & 2 & 101.88 & & 2 & 636.00 \\
\hline & 3 & 152.82 & & 3 & 954.00 \\
\hline & 4 & 203.76 & & 4 & 1272.00 \\
\hline & 5 & 254.70 & & 5 & 1590.00 \\
\hline & 6 & 305.64 & & 6 & 1908.00 \\
\hline \multirow{6}{*}{$\begin{array}{l}\text { Medicare J2275 unit } \\
\text { measure billing per } 10 \\
\text { mg } \\
\text { ASP }+6 \%=\$ 2.83 / 10 \mathrm{mg}\end{array}$} & 7 & 356.58 & & 7 & 2226.00 \\
\hline & 8 & 407.52 & & 8 & 2544.00 \\
\hline & 9 & 458.46 & & 9 & 2862.00 \\
\hline & 10 & 509.40 & & 10 & 3180.00 \\
\hline & 11 & 560.34 & & 11 & 3498.00 \\
\hline & 12 & 611.28 & & 12 & 3816.00 \\
\hline
\end{tabular}

${ }^{\star}$ Based on experience and conjecture; not clinically or experimentally validated. IT = intrathecal; ASP = average sales price. 
Table 7. Cost Comparison of a high-end and a low-end it medication versus a brand name oral drug regimen and generic drug regimen (years).*

\begin{tabular}{|c|c|c|}
\hline Drug Regimen and Dose & $\begin{array}{c}\text { Time } \\
\text { (years) }\end{array}$ & $\begin{array}{l}\text { Average } \\
\text { Cost }(\$)\end{array}$ \\
\hline IT Prialt ${ }^{\circledast}$ & 0 & 0 \\
\hline \multirow{6}{*}{$\begin{array}{l}\text { Average dose } 4 \mathrm{mcg} / \text { day in } 20-\mathrm{mL} \\
\text { Medtronics pump } \\
\text { Medicare J2278 unit measure billing } \\
\text { per } 1 \mathrm{mcg}\end{array}$} & 1 & 9374.40 \\
\hline & 2 & $18,748.80$ \\
\hline & 3 & $28,123.20$ \\
\hline & 4 & $37,497.60$ \\
\hline & 5 & $46,872.00$ \\
\hline & 6 & $56,246.40$ \\
\hline \multirow{4}{*}{$\mathrm{ASP}+6 \%=\$ 6.51 / \mathrm{mcg}$} & 7 & $65,620.80$ \\
\hline & 8 & $74,995.20$ \\
\hline & 9 & $84,369.60$ \\
\hline & 10 & $93,744.00$ \\
\hline IT Morphine & 0 & 0 \\
\hline \multirow{4}{*}{$\begin{array}{l}\text { Average dose } 6 \mathrm{mg} / \text { day in Medtronics } \\
20 \text {-mL pump }\end{array}$} & 1 & 611.28 \\
\hline & 2 & 1222.56 \\
\hline & 3 & 1833.84 \\
\hline & 4 & 2445.12 \\
\hline \multirow{2}{*}{$\begin{array}{l}\text { Medicare J2275 unit measure billing } \\
\text { per } 10 \mathrm{mg}\end{array}$} & 5 & 3056.40 \\
\hline & 6 & 3667.68 \\
\hline \multirow{4}{*}{$\mathrm{ASP}+6 \%=\$ 2.80 / 10 \mathrm{mg}$} & 7 & 4278.96 \\
\hline & 8 & 4890.24 \\
\hline & 9 & 5501.52 \\
\hline & 10 & 6112.80 \\
\hline
\end{tabular}

\begin{tabular}{|c|c|c|}
\hline Drug Regimen and Dose & $\begin{array}{c}\text { Time } \\
\text { (years) }\end{array}$ & $\begin{array}{l}\text { Average } \\
\text { Cost }(\$)\end{array}$ \\
\hline Oral Brand Name Regimen & 0 & 0 \\
\hline \multirow{10}{*}{$\begin{array}{l}\text { Oxycontin }^{\star} 80 \mathrm{mg} \text { TID } \\
\text { Percocet }{ }^{\circledR} 10 / 325 \mathrm{mg} 8 \mathrm{x} \text { day } \\
\text { Lyrica }^{\star} 150 \mathrm{mg} \text { BID } \\
\text { Cymbalta }^{\circ} 60 \mathrm{mg} \text { QD } \\
\text { Klonopin }^{\star} 1 \mathrm{mg} \text { BID } \\
\text { Ambien CR } 12.5 \mathrm{mg} \text { QHS }\end{array}$} & 1 & 34,272 \\
\hline & 2 & 68,544 \\
\hline & 3 & 102,816 \\
\hline & 4 & 137,088 \\
\hline & 5 & 171,360 \\
\hline & 6 & 205,632 \\
\hline & 7 & 239,904 \\
\hline & 8 & 274,176 \\
\hline & 9 & 308,448 \\
\hline & 10 & 342,720 \\
\hline Oral Generic Regimen & 0 & 0 \\
\hline \multirow{10}{*}{$\begin{array}{l}\text { Methadone }^{\circledast} 10 \mathrm{mg} \text { QID } \\
\text { Oxycodone }^{\oplus} 15 \mathrm{mg} \text { QID } \\
\text { Gabapentin }^{\circledast} 400 \mathrm{mg} \text { QID } \\
\text { Desipramine }^{\circledast} 10 \mathrm{mg} \text { TID } \\
\text { Trazodone }^{\oplus} 50 \mathrm{mg} \text { QHS }\end{array}$} & 1 & 3816 \\
\hline & 2 & 7,632 \\
\hline & 3 & 11,448 \\
\hline & 4 & 15,264 \\
\hline & 5 & 19,080 \\
\hline & 6 & 22,896 \\
\hline & 7 & 26,712 \\
\hline & 8 & 30,528 \\
\hline & 9 & 34,344 \\
\hline & 10 & 38,160 \\
\hline
\end{tabular}

*Based on experience and conjecture; not clinically or experimentally validated. IT = intrathecal; ASP = average sales price.

regimen; Table 7 provides projected expenses for each regimen when utilized over 10 years (146-149).

As previous analyses have demonstrated, IT therapy is associated with relatively high initial costs for device implantation, as well as monthly fees for pump refilling and/or reprogramming, regardless of which agent is administered (Tables 8-10) (143-149). Yet, even after factoring in these added expenses, IT delivery of either Prialt ${ }^{\circ}$ or morphine is less costly than a brand name oral regimen. As Figure 2 demonstrates, the cost of an oral brand name regimen exceeds that of IT morphine after 7 months of treatment; after 10 months, IT Prialt $\circledast$ is also found to be less expensive than brand name oral therapy (146-151). After 10 years of treatment, brand name oral therapy remains the most costly option (Fig. 3) (146-151). Generic oral therapy represents the least expensive treatment option when compared with a brand name oral regimen or IT drug delivery regardless of the length of treatment (146-149); however, the use of only oral generics in clinical practice is rarely done. Instead, treatment with IT morphine may provide a comparable alternative to the least costly generic oral therapy.

Notably, the data used in this example are based on IT therapy with a programmable drug delivery system, as opposed to a constant flow device. At present, the US market largely utilizes programmable pumps because they provide a high level of patient satisfaction by allowing for dose adjustments that correspond with pain fluctuations $(62,152)$. Medicare reimbursement varies for programmable and constant flow devices, thus costs may be different depending on the pump 
Table 8. Initial pump expense and monthly refill costs. *

\begin{tabular}{|c|c|c|c|}
\hline \multicolumn{4}{|l|}{ Initial Pump Expense } \\
\hline Procedure & Physician Reimbursement (\$) & Clinic Reimbursement (\$) & Cost $(\$)$ \\
\hline Screening test & 89 & 474 & 563 \\
\hline Catheter insertion & 365 & 2777 & 3142 \\
\hline Pump placement & 384 & 12,282 & 12,666 \\
\hline \multicolumn{4}{|l|}{ Monthly Refill Cost } \\
\hline Procedure & Physician Reimbursement (\$) & Clinic Reimbursement (\$) & Cost $(\$)$ \\
\hline Refill & 87 & 188 & 275 \\
\hline \multirow[t]{2}{*}{ Pump reprogramming } & 51 & 163 & 214 \\
\hline & & TOTAL & 489 \\
\hline
\end{tabular}

${ }^{*}$ Based on experience and conjecture; not clinically or experimentally validated. IT = intrathecal; ASP = average sales price.

Table 9. Monthly costs, including initial pump cost and refills. *

\begin{tabular}{|c|c|c|c|c|c|}
\hline Drug Regimen and Dose & $\begin{array}{c}\text { Time } \\
\text { (months } / 30 \\
\text { days) }\end{array}$ & $\begin{array}{l}\text { Average } \\
\text { Cost }(\$)\end{array}$ & Drug Regimen and Dose & $\begin{array}{c}\text { Time } \\
\text { (months/30 } \\
\text { days) }\end{array}$ & $\begin{array}{l}\text { Average } \\
\text { Cost }(\$)\end{array}$ \\
\hline IT Prialt $^{\circ}$ & 0 & $16,371.00$ & IT Morphine & 0 & $16,371.00$ \\
\hline \multirow{7}{*}{$\begin{array}{l}\text { Average dose } 4 \mathrm{mcg} / \text { day in } 20-\mathrm{mL} \\
\text { Medtronics pump } \\
\text { Medicare J2278 unit measure billing } \\
\text { per } 1 \mathrm{mcg}\end{array}$} & 1 & $17,641.20$ & \multirow{7}{*}{$\begin{array}{l}\text { Average dose } 6 \mathrm{mg} \text { /day in Medtron- } \\
\text { ics } 20 \text {-mL pump } \\
\text { Medicare J2275 unit measure billing } \\
\text { per } 10 \mathrm{mg}\end{array}$} & 1 & $16,910.94$ \\
\hline & 2 & $18,911.40$ & & 2 & $17,450.88$ \\
\hline & 3 & $20,181.60$ & & 3 & $17,990.82$ \\
\hline & 4 & $21,451.80$ & & 4 & $18,530.76$ \\
\hline & 5 & $22,722.00$ & & 5 & $19,070.70$ \\
\hline & 6 & $23,992.20$ & & 6 & $19,610.64$ \\
\hline & 7 & $25,262.40$ & & 7 & $20,150.58$ \\
\hline \multirow{5}{*}{$\begin{array}{l}\text { ASP }+6 \%=\$ 6.51 / \mathrm{mcg} \\
\text { Refills performed once a month }\end{array}$} & 8 & $26,532.60$ & \multirow{5}{*}{$\begin{array}{l}\text { ASP }+6 \%=\$ 2.83 / 10 \mathrm{mg} \\
\text { Refills performed once a month }\end{array}$} & 8 & $20,690.52$ \\
\hline & 9 & $27,802.80$ & & 9 & $21,230.46$ \\
\hline & 10 & $29,073.00$ & & 10 & $21,770.40$ \\
\hline & 11 & $30,343.20$ & & 11 & $22,310.34$ \\
\hline & 12 & $31,613.40$ & & 12 & $22,850.28$ \\
\hline
\end{tabular}

${ }^{*}$ Based on experience and conjecture; not clinically or experimentally validated. IT = intrathecal; ASP = average sales price.

used. Additionally, this cost comparison assumes that no supplemental oral medications were added to the IT models. Although there are potential advantages from both a clinical and economic standpoint to minimizing oral opioids following internalization-especially if the pain areas targeted by the oral agents overlap with those treated with IT therapy-many patients who are implanted with an IT pump continue to require 1 or more oral medications to maintain effective analgesia.
This expense must be considered when assessing the potential impact of long-term intraspinal drug administration; if the patient continues with their oral regimen while utilizing an implantable drug delivery system, then the cost of the oral agents would be additive.

\subsection{Panel Recommendations.}

Chronic pain management should always follow a step-wise approach-progressing to a more aggressive 
Table 10. Yearly costs, including initial pump and refills. *

\begin{tabular}{|c|c|c|c|c|c|}
\hline Drug Regimen and Dose & $\begin{array}{c}\text { Time } \\
\text { (years) }\end{array}$ & $\begin{array}{l}\text { Average } \\
\text { Cost }(\$)\end{array}$ & Drug Regimen and Dose & $\begin{array}{c}\text { Time } \\
\text { (years) }\end{array}$ & $\begin{array}{l}\text { Average } \\
\text { Cost (\$) } \\
\end{array}$ \\
\hline IT Prialt $^{\oplus}$ & 0 & 0 & IT Morphine & 0 & 0 \\
\hline \multirow{6}{*}{$\begin{array}{l}\text { Average dose } 4 \mathrm{mcg} / \text { day in } 20-\mathrm{mL} \\
\text { Medtronics pump } \\
\text { Medicare J } 2278 \text { unit measure billing } \\
\text { per } 1 \mathrm{mcg}\end{array}$} & 1 & $31,613.40$ & \multirow{9}{*}{$\begin{array}{l}\text { Medicare J2275 unit measure billing } \\
\text { per } 10 \mathrm{mg} \\
\text { ASP }+6 \%=\$ 2.83 / 10 \mathrm{mg} \\
\text { Refills performed once a month }\end{array}$} & 1 & $22,850.28$ \\
\hline & 2 & $46,855.80$ & & 2 & $29,329.56$ \\
\hline & 3 & $62,098.20$ & & 3 & $35,808.84$ \\
\hline & 4 & $77,340.60$ & & 4 & $42,288.12$ \\
\hline & 5 & $92,583.00$ & & 5 & $48,767.40$ \\
\hline & $\begin{array}{l}\quad 6 \\
\text { (including } \\
\text { a pump } \\
\text { replacement } \\
\$ 12,666)\end{array}$ & $120,491.40$ & & $\begin{array}{l}\quad 6 \\
\text { (including } \\
\text { a pump } \\
\text { replacement } \\
\$ 12,666)\end{array}$ & $67,912.68$ \\
\hline \multirow[t]{4}{*}{ Refills performed once a month } & 7 & $135,733.80$ & & 7 & $74,391.36$ \\
\hline & 8 & $150,976.20$ & & 8 & $80,871.24$ \\
\hline & 9 & $166,218.60$ & & 9 & $87,350.52$ \\
\hline & 10 & $181,461.00$ & & 10 & $93,829.00$ \\
\hline
\end{tabular}

${ }^{\star}$ Based on experience and conjecture; not clinically or experimentally validated. IT = intrathecal; ASP = average sales price.

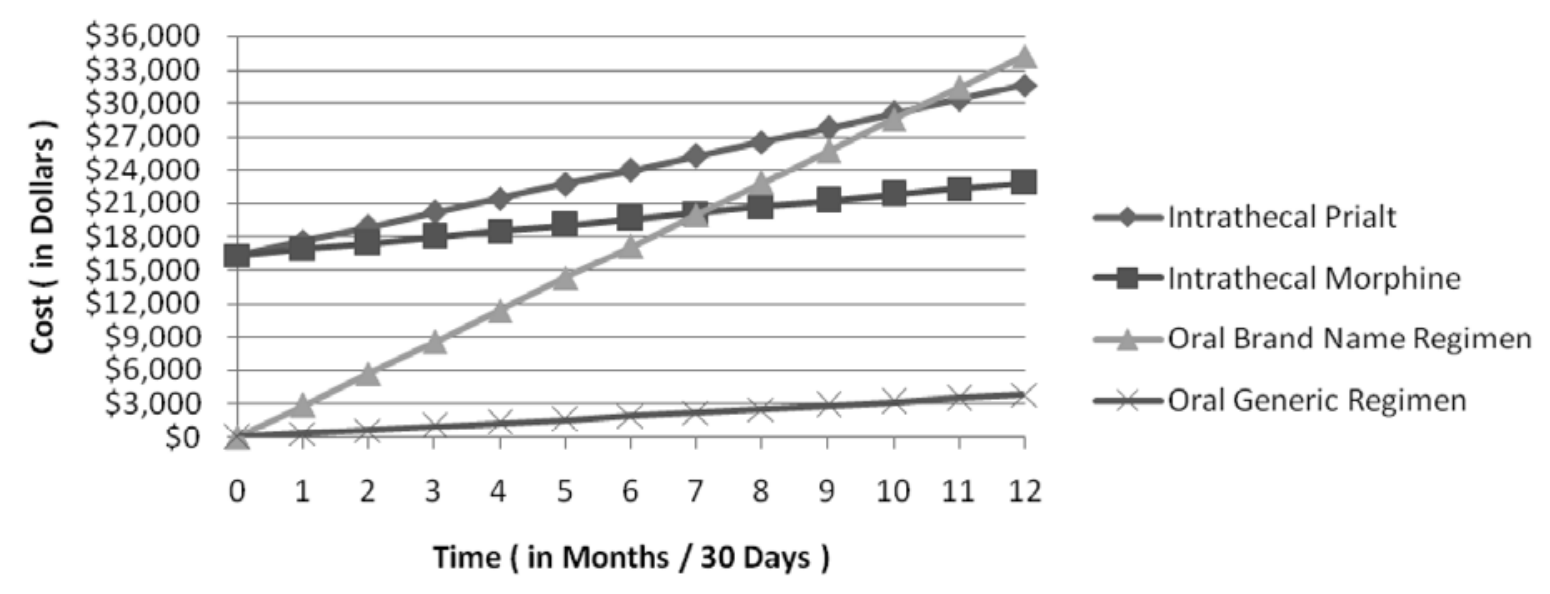

Fig. 2. Cost comparison of 2 intrathecal medications to an oral brand name medication regimen and an oral generic medication regimen. Based on experience and conjecture; not clinically or experimentally validated.

treatment as necessary-while considering associated financial cost. For those who meet all patient selection criteria for IT therapy, an implantable drug delivery system may offer an alternative method to maintain pain relief without necessarily increasing the cost of care.
However, even an appropriately selected patient will have poor outcomes if they are not properly managed, which will negate any potential cost benefit associated with IT delivery. 


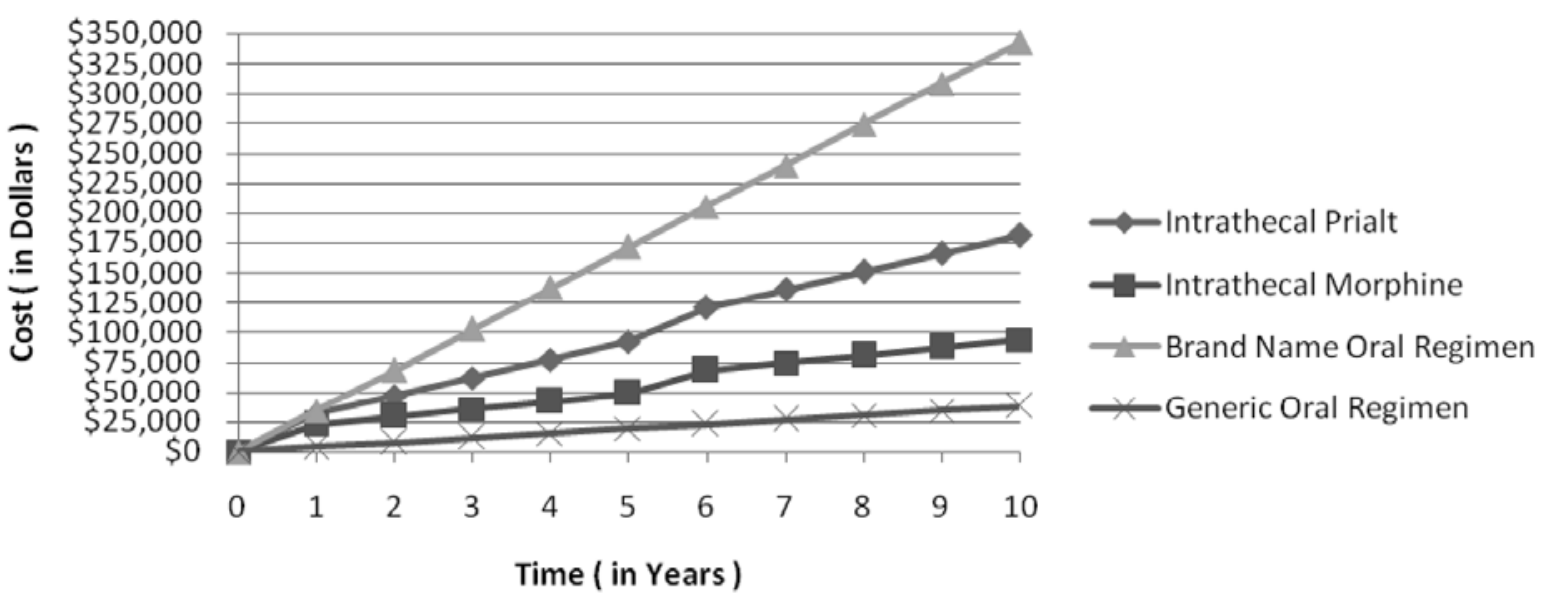

${ }^{*}$ Hospital outpatient rates are based on the average standardized operating amount ( $\left.\$ 5128.41\right)$ plus the capital standard amount (\$424.17), as published in the Federal Register, Volume 73, Number 193, October 3, 2008, CMS-1390-N. Physician payment is determined by multiplying the sum of the 3 component RVUs by the 2009 conversion factor $(\$ 36.0666)$, as published in the Federal Register, Volume 73, Number 224, November 19, 2008. Final reimbursement is adjusted by the Geographic Practice Cost Indices $(111,112,114,115)$.

Fig. 3. Cost comparison of 2 intrathecal medications to an oral brand name medication regimen and an oral generic medication regimen.*

\subsection{Pharmacologic Issues}

To optimize IT therapy, management of pain and adverse effects often requires combinations of drugs to achieve appropriate analgesia. In addition, patient-centered treatment regimens typically seek to reduce the number of pump refills, as this minimizes not only cost and inconvenience, but also risk of infection associated with the refill process. To accomplish this, IT drugs are frequently used at higher concentrations than are commercially available. As a result, clinicians tend to rely on compounding as a means of providing individualized IT formulations.

Drug compounding is the mixture or modification of ingredients to prepare a specialized medication for clinical use. It includes dilution, reconstitution, admixture, repackaging, and many other manipulations of sterile products. Although compounding for many delivery routes may pose a minimal threat to patient safety, improperly prepared or contaminated drugs intended for direct administration into the CNS could have catastrophic effects and are considered high risk. It is, therefore, essential that clinicians and pharmacists alike understand the drugs, preservatives, and other excipients used in formulating these preparations and that they observe proper compounding procedures at all times.

\subsection{Safety Considerations}

At present, preservative-free morphine sulfate (Infumorph®, Baxter; Astramorph®, AstraZeneca) and ziconotide (Prialt $\circledast$, Elan) are the only drugs approved by the FDA for IT therapy (153-155). IT morphine is often prescribed in concentrations that exceed commercially available preparations $(25 \mathrm{mg} / \mathrm{mL})$ and thus requires modification prior to IT use (15). Morphine and ziconotide can also be used in combination with other drugs-such as clonidine, hydromorphone, bupivicaine, gabapentin, and fentanyl-when monotherapy is inadequate (15). To ensure safety and efficacy, prescribing physicians and compounding pharmacists must consider a number of critical parameters, including compatibility, concentration and solubility, tonicity, stability, and sterility.

\subsection{Compatibility.}

Many of the commercially available drugs that are FDA-approved for other injectable routes are not compatible for IT use due to the presence of preservatives or other excipients that may be neurotoxic. Benzyl alcohol, phenol, formaldehyde, and methylparaben preservatives are all reported to be neurotoxic when used intrathecally $(156,157)$. Based on case reports, acetate buffers, ethanol concentrations of $10 \%$ or greater, $\mathrm{pH}$ 
levels below 4 or above 9, and certain drug products may also be unsuitable for IT use (158). Neurologic complications have been identified following the use of IT drugs containing trace contaminants (159). To ensure that IT therapies are free of potentially dangerous ingredients, both the prescribing physician and the compounding pharmacist should be aware of all formulation components, particularly for admixtures, where the ingredients of each component drug must be taken into account.

\subsection{Concentration and Solubility.}

As part of the FDA approval process, drugs are commonly tested at varying concentrations, and the safety of a drug must be demonstrated at concentrations that exceed the final approved strength. However, to maximize the interval between pump refills, drugs used for long-term IT therapy may be compounded at concentrations exceeding the approved strength. One must carefully consider the safety of administering higher concentrations of drug to the IT space, where the margin of neurotoxicity safety may be narrow (62).

Compounding drugs at higher concentrations may also lead to precipitation. It is vital that known solubility limits be observed when high-concentration formulations are prepared. Because solubility is also affected by temperature, formulations must be prepared at temperatures that do not exceed body temperature to prevent precipitation of oversaturated solutions. Furthermore, solubility decreases when drugs are combined, and data regarding the solubility of drugs in admixtures are limited. Finally, drug efficacy and solubility are affected by $\mathrm{pH}(160)$ and by the presence of ions such as chloride (62), both of which differ from drug to drug. Thus, careful attention must be paid to a number of factors that can affect drug concentration and solubility.

\subsection{Tonicity.}

Ideally, IT drug solutions should be isotonic to the CSF (approximately $300 \mathrm{mOsm} / \mathrm{L})(15,62,161)$ to maintain equilibrium in the IT space. The overall tonicity of a compounded drug depends on the sum of its components, and the ability of CSF movement to compensate for deviations in tonicity depends, in part, on the flow rate of the pump (62). To achieve satisfactory tonicity for high-concentration formulations and for drug admixtures, sterile preservative-free water may be more appropriate as a vehicle than sterile saline (62).
Table 11. Criteria for selecting a compounding pharmacy $(6,125)$

- Facility must be immaculately clean and maintain high standards for air quality

- Pharmacists and other personnel should be trained in aseptic principles and practices

- Pharmacists and other personnel must have a thorough understanding of sterilization and solution stability principles

- Solutions should be compounded in accordance with the United States Pharmacopoeia and American Society of Health-System Pharmacists standards

\subsection{Stability.}

The effort to minimize refills by increasing drug concentrations and increasing reservoir volumes raises the issue of drug stability. Drugs used for long-term therapy via an IT pump must remain stable at body temperature for months; however, stability data are lacking for most IT agents (with the exception of morphine), and the effects of drug admixtures on the stability of their individual components are poorly understood (62).

\subsection{Sterility.}

The consequences of administering a nonsterile drug into the IT space are obvious, and CNS infections following pump implantation have been linked to compound formulations $(84,162)$. To ensure the quality and safety of IT preparations, compounding should be performed in immaculately clean facilities that maintain high standards for air quality; it is also essential that compounding pharmacists have a thorough understanding of aseptic procedures (Table 11) $(15,161)$.

\subsection{Regulatory Considerations, Standards, and Guidelines}

The practice of pharmacy is regulated at the state level, although certain aspects of compliance are overseen by the FDA (163-165). FDA regulation of compounding pharmacy is a controversial issue that revolves around the effort of physicians and pharmacists to ensure patient access to individualized therapies on the one hand, and the FDA's view that all compounded drugs are new agents and thus unsafe without full testing on the other hand. For reasons of time and expense, the use of individualized therapies often precludes complete safety trialing. Compounding pharmacies at 
present are exempt from many FDA regulations that apply to drug manufacturing, but must remain statecompliant and are limited to compounding drugs pursuant to valid prescriptions for individual patient needs. They are not allowed to engage in large-scale "manufacturing" for future or unidentified patients. Several of the FDA's concerns regarding drug compounding are particularly relevant for IT therapy, specifically those pertaining to the use of higher-than-approved drug concentrations and the compatibility and stability of compounded drug admixtures.

Standards and guidelines for pharmaceutical compounding practices have been established by the United States Pharmacopoeia (USP) and the American Society of Health-System Pharmacists (ASHP), both of which provide frequent revisions and updated bulletins online (166-168). Many of the USP and ASHP guidelines pertain to the assurance of sterility. These agencies define 3 risk levels for compounded sterile products (CSPs) based on the probability of microbial or foreign material contamination (166-168). Current guidelines assign the highest risk level (Level 3) for all "CSPs that lack effective antimicrobial preservatives" (166-168). Since preservatives are contraindicated for IT use, all IT drugs are classified as high risk. The preparation of CSPs is covered in depth in USP General Chapter $<797>$, Pharmaceutical Compounding-Sterile Preparations (168).

In addition, Polyanalgesic Consensus Guidelines $(15,161)$ have been established based on extensive literature reviews and expert panel discussions. These are invaluable resources to the practicing pain physician, as they address clinical and preclinical data for specific IT drugs; provide rationale for drug selection, dosage, and concentration; and offer considerations for compounding above and beyond the USP and ASHP guidelines.

\subsection{Intrathecal Therapies Trialing}

Implementation of an IT therapy trial typically serves as a final step in the patient selection process due to current insurance requirements (eg, Medicare) and widespread physician practices. Traditionally, patient response to analgesic administration during a trial has been used to determine the potential pain relief from IT therapy and to gauge patient level of commitment to treatment. Despite immediate short-term benefits, the value of a trial as an accurate predictor of subsequent IT therapeutic success or failure is difficult to corroborate. Trialing as an extrapolative screening tool for IT therapy requires close examination of how effectively the process determines who should or should not receive IT therapy.

\subsection{Trialing Methodologies.}

Although IT trialing is commonly utilized prior to device implantation, the methods and locations in which testing is performed vary greatly. Screening techniques are implemented via epidural or IT delivery, with the selected treatment administered through single injection, multiple injections, or continuous infusion. A trialing method is determined largely based on the patient's overall condition, the physician's preference, availability of facilities, practice environment, and insurance/Medicare coverage provided $(47,121)$. An evaluation of the National Outcomes Registry for Low Back Pain found that most trials were performed at a hospital as an inpatient procedure (72\%), as opposed to an outpatient procedure in a hospital or ambulatory surgery center (16\% and $12 \%$, respectively) (47). More than half of the trials in this report utilized a continuous epidural infusion, and the majority of patients received only morphine (47). Results showed that the mean trial duration was $3.5 \pm 5.4$ days (47). Importantly, there is no published data to support the use of one screening technique over another; each trialing method has unique advantages and disadvantages, and the clinician must decide, which technique-if any-is best suited for the patient (Table 12).

\subsection{Reassessing Trial Goals.}

The goal of a trial is to assist clinicians in the identification of appropriate candidates for IT therapy. Positive quantitative or qualitative patient response to an IT opioid trial has routinely been thought to translate into successful long-term IT therapy. Trial success has traditionally been set at $50 \%$ or greater improvement in pain score, although standards for trial failure have been less concrete $(10,11)$. A trial measures pain relief using an accepted tool, such as the visual analog scale, compared against baseline measurements to assess patterns of response and indications of adequate pain reduction-with minimal incidence of intolerable adverse effects-to help qualify the patient for pump implantation $(10,11)$. The historical perspective on trial goals was originally shaped by a limited array of approved IT opioid agents (primarily morphine) and arbitrary end points related to their pharmacologic effects. However, advances in pain practice attributable to novel nonopioid IT agents have broadened treatment strategies and devalued the relationship between opioid trial response and long-term benefit (169). Furthermore, discrepancies among comparative pain relief data associated with opioid trial agents and other drug classes or 
Table 12. Screening trial methods: advantages and disadvantages

\begin{tabular}{|c|c|c|c|c|c|c|c|}
\hline & \multicolumn{2}{|c|}{ Single Injection } & \multicolumn{2}{|c|}{ Multiple Injections } & \multicolumn{2}{|c|}{ Continuous Infusion } & \multirow{2}{*}{ No Trial } \\
\hline & Epidural & Intrathecal & Epidural & Intrathecal & Epidural & Intrathecal & \\
\hline 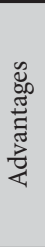 & $\begin{array}{l}\text { Low cost } \\
\text { Minimal time } \\
\text { commitment } \\
\text { No PDPH }\end{array}$ & $\begin{array}{l}\text { Low cost } \\
\text { Minimal time } \\
\text { commitment }\end{array}$ & $\begin{array}{l}\text { No PDPH } \\
\text { Can use placebo } \\
\text { control }\end{array}$ & $\begin{array}{l}\text { Can use pla- } \\
\text { cebo control }\end{array}$ & $\begin{array}{l}\text { No PDPH } \\
\text { Less placebo } \\
\text { response }\end{array}$ & $\begin{array}{l}\text { Mimics chronic } \\
\text { drug infusion } \\
\text { Less placebo } \\
\text { response }\end{array}$ & $\begin{array}{l}\text { No cost } \\
\text { No time } \\
\text { commitment } \\
\text { No possibility for } \\
\text { placebo response }\end{array}$ \\
\hline 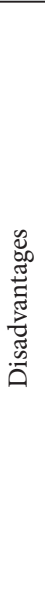 & $\begin{array}{l}\text { High placebo } \\
\text { response } \\
\text { Systemic drug } \\
\text { effect } \\
\text { Does not mimic } \\
\text { chronic drug } \\
\text { infusion }\end{array}$ & $\begin{array}{l}\text { High placebo } \\
\text { response } \\
\text { PDPH may } \\
\text { interfere with } \\
\text { trial } \\
\text { Does not mimic } \\
\text { chronic drug } \\
\text { infusion }\end{array}$ & $\begin{array}{l}\begin{array}{l}\text { Systemic drug } \\
\text { effect }\end{array} \\
\text { Does not mimic } \\
\text { chronic drug } \\
\text { infusion }\end{array}$ & 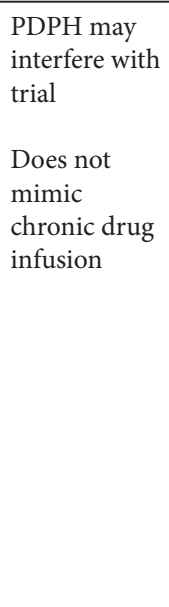 & $\begin{array}{l}\text { High cost } \\
\text { Systemic drug } \\
\text { effect } \\
\text { Labor intensive } \\
\text { Does not mimic } \\
\text { chronic drug } \\
\text { infusion } \\
\text { Risk of infection } \\
\text { Many insurances } \\
\text { do not cover home } \\
\text { infusion (includ- } \\
\text { ing Medicare for } \\
\text { noncancer pain) }\end{array}$ & $\begin{array}{l}\text { High cost } \\
\text { Labor intensive } \\
\text { PDPH may inter- } \\
\text { fere with trial } \\
\text { Risk of infection } \\
\text { Many insurances } \\
\text { do not cover home } \\
\text { infusion (includ- } \\
\text { ing Medicare for } \\
\text { noncancer pain) }\end{array}$ & $\begin{array}{l}\text { Many insurers will } \\
\text { not cover device } \\
\text { implantation with- } \\
\text { out first conducting } \\
\text { a preoperative trial }\end{array}$ \\
\hline
\end{tabular}

$\mathrm{PDPH}=$ postdural puncture headache.

combinations difficult to use in trial settings heighten the ambiguity of trial goals (170).

Trends in pre- and post-implantation responses are frequently examined in the literature in an attempt to characterize the role of IT trials in the patient selection process. Limited data suggest that IT trials predict outcomes; the only evidence that suggests there is predictive value comes from retrospective studies. For instance, in a retrospective study of 29 patients with noncancer pain, $86 \%$ of patients reported their pain relief to be better or excellent in comparison with their trial experience during a mean follow-up period of 31 months (117). In another retrospective study of 86 patients with noncancer pain undergoing opioid trials, Dominguez et al identified possible patient trends in responsiveness during trials that were predictive of longterm IT requirements post-implantation (171); however, lack of similar studies prevents this retrospective study from generalizing all trials as useful predictive steps. Furthermore, studies do not consistently demonstrate a positive relationship between a successful trial and subsequent therapeutic success. In a prospective study of
18 patients with noncancer pain, all subjects achieved a pain decrease of greater than $50 \%$ during trial with IT morphine or sufentanyl; yet, following implantation, $39 \%$ of the same patients experienced no pain reduction during a mean follow-up time of 2.4 years (172). Another study showed that patients attaining good pain relief through a single-dose trial may experience inadequate benefit from long-term IT infusion (173). Additionally, in select patient populations, such as those with fibrosis, restrictions in the epidural space may distort trial results and misrepresent the level of response that could be obtained with a permanent pump $(10,11)$. Trial outcomes frequently lack consistency with actual therapeutic response, since good or inadequate pain relief demonstrated during an IT trial may not materialize once actual treatment commences.

\subsection{Limitations and Compounding Effects.}

The inability of a trial setting to simulate conditions of the intended IT environment and anticipate effects of chronic treatment has impeded the solidification of best practices for trial protocols; common trial- 
ing methods incompetently approximate the planned mechanisms of treatment. Trial durations also have a considerable range, typically lasting several days, but spreading anywhere from a few hours to several weeks. The practice of tailoring trials around patient characteristics is a consequence of the lack of current evidence to stratify any particular method over another (121).

Despite the paucity of guidelines promulgated for IT trialing, published trial guides, expert consensus, and review articles have invariably called for an IT therapy trial to provide clinical rationale for permanent pump and IT catheter implantation $(15,88,174)$, yet fall short of adequately or accurately predicting long-term effectiveness. In one monograph detailing recommended trial protocols, a pump manufacturer acknowledges the limitations of a positive trial in its inability to "guarantee a positive longer-term outcome" (174). Current Medicare guidelines also mandate a preliminary trial of intraspinal opioid drug administration via a temporary IT/epidural catheter to "substantiate adequately acceptable pain relief and degree of side effects (including effects on the activities of daily living) and patient acceptance" (175). Although no current standards exist for IT trials and expectations vary immensely, the 2007 Polyanalgesic Consensus Conference panelists recommended the continuation of trialing using a strategy determined by the performing physician, until data deem the trials unnecessary (15). In earlier statements, the 2003 Polyanalgesic Consensus Conference panelists addressed "the potential for varied effects from differences in dosage, infusion rate, and concentration" and noted that "the time-consuming strategy of conducting trials systematically by varying only 1 parameter at a time might be best for judging drug effects, but is impractical in most clinical settings" (161). In a retrospective chart review of 86 individuals treated with a rotation of long-acting opioids for noncancer pain, the first of 5 tried opioids was adequately effective in only $36 \%$ of patients (176); however, substitution of new opioids cumulatively increased the percentage of efficacy and tolerability, with the fifth consecutive agent yielding response in $14 \%$ of patients (176). As demonstrated by the continued response in the remaining subsets of patients, efficacy rates associated with individual opioids did not provide predictive value for other opioids to safely improve analgesia (176). The same substitution process may offer similar advantages in the IT therapy setting to fully assess the potential benefit from IT opioids, increase patient likelihood of response, and maximize pain relief outcomes over time. The 2003 Polyan- algesic Consensus Conference panelists also conceded the difficulty of devising dosing guidelines that pertain to all patients given the currently available armamentarium for IT infusion (161). The infinite potential combinations of drug admixtures and doses, occurring with increasing frequency, are impractical to assess during trials and could have effects that are additive, subtractive, or synergistic (161). Some newer IT agents, such as the calcium channel blocker ziconotide, cultivate new challenges in meeting trial criteria set by insurance companies. Unlike opioids, which produce their effect within hours of administration, ziconotide may require several days of administration to demonstrate effectiveness. Consequently, ziconotide trials may require more rapid titration than would otherwise be used for chronic administration, and unfortunately, rapid administration of IT ziconotide can produce therapy-limiting adverse effects (169). Thus, evolving pharmacologic options hamper the standardization of trial design.

Separation of the powerful placebo effects of therapy constitutes another trial limitation that compromises the assessment of efficacy and elimination of toxicity issues. The limited duration of most trials cannot rule out placebo effects, which may explain patient response to some trials of IT analgesics, but failure to sustain improvement upon initiation of therapy. Such instances further detract from the predictive value of trialing. However, a placebo response is not necessarily sufficient to withhold actual treatment due to the lack of specificity of the response to an isolated trial with a selected agent (177). A 2001 publication recommends maximizing the duration of the trial to guard against a placebo response, while conceding that placebo effects can last up to a year (177). The researcher also acknowledged the impact of trial time on occurrence of complications, including the dressing and tubing changes, which may exacerbate infection (177). Several strategies have been offered to circumvent placebo-related effects during the trial period and obtain a more objective analysis of response. One such method entails a 2-phase trial approach to quantitatively establish an optimal starting dose for pain relief, followed by a crossover, double-blind, placebo-controlled trial to eliminate potential physician or patient bias (170). Utilizing this trial set up, the researcher found that goodto-excellent pain relief was reported by $73 \%$ of study participants post-implantation (170). Although they present tactics to control for placebo response during the trial phase, studies that report positive response following initiation of pump therapy are limited by the 
absence of long-term data demonstrating continuous benefit after 1 year. In addition, subjects who do not exhibit a positive response during a given trial may respond to alternate drugs or combination therapies.

Trialing assessments are largely based on the assumption that patient response to opioids will be clearly defined. However, failure of pain relief to endure beyond the trial can also be accounted for by the development of tolerance and opioid-induced hyperalgesia, which cannot be evaluated during the brief trial period. Careful titration or rotation to other opioids or medication combinations are occasionally required to maximize analgesia and provide adequate pain relief, a strategy that is not usually a trial component and would require lengthy trial duration (178). Trials are also restricted by their inability to eliminate risk for toxicity and adverse effects associated with the invasive procedure, the opioid, or the modality. Perioperative risks, including those conferred by the surgical procedure of implanting an infusion system, cannot be anticipated during a trial; these and other independent shortcomings associated with trialing warrant careful consideration before validating the role of an IT trial.

\subsection{Panel Recommendation}

\subsection{Alternative Psychological-Based Strategies}

Clinical studies have historically characterized IT therapy as well tolerated, providing analgesia that outweighs adverse effects, which can typically be managed through careful patient selection and monitoring (161). For example, adverse effects of morphine can be managed by rotation to hydromorphone, addition of an agent such as bupivacaine, or reducing the morphine dose. In addition, one of the more significant risks of IT therapy is the development of a catheter-tip inflammatory mass that expands, leading to cord compression with signs of myelopathy (73), which may be minimized by careful dose selection and positioning of the catheter. Thus, concentrating clinical management on tolerable post-implantation adverse effects by refining IT pump regimens would prevent unnecessary involvement of vulnerable patients in a trial period. To minimize the physical and psychological burden on the patient, better utilization of available IT safety and efficacy evidence-in combination with a strategic, multifaceted patient selection process-would serve as a practical alternative to trialing.

The panel recommends reconsideration of mandatory IT trials. The decision to conduct a trial should be left to the physician, but there should not be a requirement for a trial. The recommendation is based on the fact that the predictive value of trials is unsubstantiated, the absence of long-term efficacy, the lack of demonstrated safety sufficient to outweigh trial risks, the inability of trial agents to simulate the infusion rate and volume of IT medications comparable to long-term administration, and the time limitations to sufficiently monitor patient response-including potential development of tolerance and opioid-induced hyperalgesia. Lack of compatibility with emerging agents and combinations for IT drug delivery and potential complications inherent to trials themselves (ie, the probability that an implantable pump may be associated with a smaller risk of infection than a temporary catheter) should also be considered in determining trial utility during the patient selection process. For practitioners who deem a trial period necessary to proceed with implantation, an emphasis on simulating actual IT delivery-allowing sufficient time to evaluate patient response to various agents and/or drug admixtures-may be beneficial. This method can be costly, but enables the practitioner to assess the potential response to therapy and maximize pain relief outcomes over time. To help facilitate extended IT trialing, the panel supports the development of a less expensive, programmable pump with a life span of 6 to 12 months. This "trial" pump would provide for adequate time to examine the effects of IT therapy; if therapy via the "trial" pump is successful, then implantation of a permanent device may be warranted. Alternatively, the panel recommends a heavier focus on psychological evaluation as outlined in the "Associated Psychological Considerations" section, than on IT trials to safely qualify patients for pump implantation. For patients with chronic noncancer pain, a psychological evaluation may be the most valuable screen before commencing treatment and, being less invasive, would carry less risk. The presence or absence of comorbid mental disease may be equally or more predictive of IT success than an IT trial.

\subsection{Future Directions-New Technology}

Incorporation of multidisciplinary patient selection considerations into pain management algorithms effectively promotes favorable clinical outcomes of IT therapy. However, escalating needs exist to broaden the applicability of implantable drug delivery systems by addressing shortcomings of device technology and safety, efficacy, and compatibility concerns associated with approved IT agents or admixtures. Ongoing clini- 
cal investigations are facilitating therapeutic innovations to permit analgesic optimization in the subset of individuals unable to elicit satisfactory pain relief from available options.

\subsubsection{Device Enhancements.}

As the physical foundation for long-term IT pain management, pump system hardware requires progressive design to better serve individual technical needs and improve patient quality of life. Several new pump technologies have been developed to enhance treatment opportunities for select patient populations by extending IT delivery capabilities. The Prometra ${ }^{\circledR}$ Programmable Pump System is an investigational device adapted from existing technology and comprised of predominantly immobile parts to promote durability and longevity beyond 10 years (179). The fully implantable device features a positive pressure design and offers a flow rate of up to $28 \mathrm{~mL} /$ day; dosing accuracy is achieved by gate-controlled flow of morphine into a fixed-volume dose control chamber with a capacity of $20 \mathrm{~mL}$ (179). Other pump specifications include a weight of $150 \mathrm{~g}$, diameter of $71 \mathrm{~mm}$, and thickness of $20 \mathrm{~mm}$ (179). A clinical trial for Prometra ${ }^{\circledR}$ was initiated in January 2007 with primary outcome measures including safety and efficacy of programmed morphine delivery in adults suffering from intractable chronic pain (180); expanded access became available as of March 2009 (181). Recent results from the multicenter evaluation of 110 patients with chronic intractable pain and cancer pain demonstrated an overall $97.5 \%$ dose accuracy rate (181), falling within current marketed accuracy ranges of $85 \%$ to $115 \%$ (179). Accuracy rates, ranging from $96.3 \%$ to $98.7 \%$, showed no significant difference when evaluated at 4 increasing flow rate categories of 0.00 to $0.192 \mathrm{~mL} /$ day to greater than $0.40 \mathrm{~mL} /$ day (179). The efficacy of the Prometra ${ }^{\circledR}$ pump was also supported by statistically significant improvements from baseline pain measurements scored using the visual analog scale, numeric rating scale, and Oswestry disability index assessments over the course of 12 months (183). Based on meeting preestablished end points for accuracy, efficacy, and safety at desirable flow rates, anticipated 2010 FDA approval of the Prometra ${ }^{\circledR}$ pump would introduce a second programmable pump to market as an alternate treatment option for the management of chronic intractable pain using IT morphine (179).

The Medallion-another investigational implantable infusion system-is expected to enter human clinical trials in 2009 pending approval from the FDA for a pivotal clinical study (184). The system is currently being evaluated with either a $20-\mathrm{mL}$ or $40-\mathrm{mL}$ pump, each of which measures 2.6 inches in diameter and 0.72 inches thick (measuring across the flat portion of the can) (184). Both versions include a sutureless connector, a radio-opaque intrathecal catheter, and are designed to for use with an 8-year battery at $0.5 \mathrm{~mL} /$ day (184). The Medallion features a negative pressure reservoir, which operates by drawing fluid in rather than pushing fluid out. The safety advantages to this are 2-fold: 1) if there were to be a breach in the system, then body fluids would be drawn into the reservoir such that the medication would not leak out, and 2) when refilling the pump, the negative pressure draws the medication from the syringe, thus negating the need to manipulate the syringe plunger (184). The pump also includes a pressure sensor designed to detect flow resistance occurring at the catheter tip or due to kinking resulting from surgical positioning or body movement (184). Clinical studies intend to verify the accuracy of the pressure sensor, as well as the overall safety and efficacy of the Medallion system (184).

A third device currently in the developmental stages, MedStream Programmable Infusion System, features a ceramic drive system that precisely controls the infusion rate without requiring motors, gears, or rotating parts (185). With either a $20-\mathrm{mL}$ or $40-\mathrm{mL}$ reservoir, the MedStream measures $76 \mathrm{~mm}$ in diameter by $21.6 \mathrm{~mm}$ $(20 \mathrm{~mL})$ or $28.2 \mathrm{~mm}(40 \mathrm{~mL})$ in length (186). The device utilizes a SureStream intraspinal catheter intended to reduce kinking and tearing, thereby improving the reliability of treatment and minimizing the requirement for follow-up procedures (186). Flow rate accuracy has been established at $\pm 10 \%$, and fill level sensor accuracy was found to be $\pm 1 \mathrm{~mL}$ for all levels of reservoir contents when administered at temperatures ranging between $36^{\circ} \mathrm{C}$ and $42^{\circ} \mathrm{C}$ (186). Although MedStream is available for sale in select European Medicines Agency countries, the system is currently pending FDA approval in the United States (186).

Another innovative approach recently applied to the intractable pain management setting supplements existing IT drug delivery technology with an adjunctive handheld device. The Personal Therapy Manager (PTM ${ }^{\mathrm{TM}}$ ) was FDA approved in 2005 for concomitant use with the SynchroMed $®$ II (187) to help overcome recognized limitations of IT monotherapy via programmable pumps in patients with unpredictable pain management needs (188). Affording more flexibility than constant flow drug delivery systems, self-administered 
bolusing using the external patient activator device permits patient control of spontaneous pain fluctuations of various intensity levels at onset. Although patient-controlled analgesia facilitates the customization of pain relief, preset specifications-consistent with physician-prescribed dosing of morphine-prevent administrative overdose within a particular timeframe. Clinical time management is enhanced through analysis of reports on pre- and post-bolus pain scores, dosing information, and technical events to determine necessary infusion modifications, while pump refill predictions and recalculations monitor reservoir contents through an alarm-mediated feature to maintain drug availability $(150,188,189)$. Results published in 2008 from a multicenter prospective registry of 168 patients with chronic pain reveal that $85 \%$ of individuals experienced overall satisfaction with the PTM ${ }^{\mathrm{TM}}$ (189). Patients with newly implanted pumps experienced significant pain relief, as shown by a $29 \%$ reduction in visual analog scale scores following 12 months of therapy (189). Use of the device was associated with quality-of-life improvements and reduced intake of supplemental analgesic medication (189). The results support the clinical utility and safety of the device, with no related serious adverse events observed during the study (189).

As with all new technology, the PTM ${ }^{\mathrm{TM}}$ has some limitations. The device is not compatible with the Synchromed I system, thus patients with an older pump are not eligible for this adjunctive therapy. Clinicians have also reported a lack of insurance coverage for the device. Although most private insurers are paying for the PTM $^{\top \mathrm{M}}$, managed care organizations and Medicare are not providing reimbursement. It is believed that Medicare will most likely offer coverage in the future; however, at present, patients are paying for the device out-of-pocket at a cost of $\$ 500$ or less.

\subsubsection{Other Technological Considerations.}

Functional considerations for technical exploration include the development of less cumbersome system parts or more compact dimensions that would not compromise drug volume capacity, as well as methods to improve energy expenditure and reduce premature exhaustion of battery power due to changing dosing requirements (150). Although patents and studies are not yet available for new devices designed to meet current technical challenges, proposed avenues include rechargeable devices-currently in development for spinal cord stimulation-and remote magnetic control to operate electronic capillaries in a gas-driven pump modality (150). Additional innovations of catheter technology may reduce miscalculations of catheter volume, which result from discrepancies between inner and outer diameter and frequently cause regimen-related adverse effects. Furthermore, connection-enforcing designs that more robustly resist tissue stress associated with regular physical activity would decrease resultant leaks and improve reliability of therapy, whereas improved compatibility with the biological environment would minimize catheter degradation caused by internal exposures. Finally, evidence-based support for standardized and tailored surgical techniques, beyond the maximum 20-mm device-skin tissue layer separation requirement, would reduce perioperative complications and provide more flexibility in pump placement among anatomically diverse patient populations (150).

\subsection{Future Directions-New Agents}

As implantable drug delivery system technology evolves, so too does the need to evaluate the safety and efficacy of established medications, compounded formulations, and novel agents for use with newly developed and existing IT pumps (15). The armamentarium of IT agents already provides a wide variety of opioid and nonopioid formulations from which to choose, yet the addition of emerging therapies may further enable clinicians to customize treatment regimens for patients with chronic noncancer pain.

\subsubsection{Ziconotide.}

Ziconotide-a nonopioid analgesic N-type calcium channel antagonist-is the most recent agent to receive FDA approval for IT delivery $(15,189)$. Although it has been used most effectively in patients with neuropathic pain, ziconotide has also proven effective in patients with nociceptive and mixed neuropathic/nociceptive pain (15). For instance, a randomized, double-blind, placebo-controlled trial by Staats et al included 111 patients with refractory cancer- or AIDS-related pain and found that IT ziconotide was associated with statistically significant decreases in pain compared with placebo ( $53 \%$ vs $18 \%$, respectively; $\mathrm{P}<.001$ ); 5 patients in the active treatment cohort achieved total pain relief (54). In another randomized, double-blind, placebocontrolled trial by Wallace et al, 255 patients with inadequately managed noncancer pain were infused with IT ziconotide or placebo for 6 days (124). Results indicated that ziconotide was associated with statistically significant decreases in pain compared with placebo (31.2\% vs $6 \%$, respectively; $\mathrm{P} \leq .001)$ (124). Similarly, a 
randomized, double-blind, placebo-controlled trial including 220 patients with severe chronic pain reported that ziconotide reduced pain by $14.7 \%$, whereas the placebo group had only a $7.2 \%$ reduction in pain ( $P$ $=.036$ ) (123). Finally, a recent open-label, multicenter, long-term outpatient study of 644 patients found that $32.7 \%$ of patients with a high visual analog pain score $(\geq 50 / 100)$ at baseline had at least a $30 \%$ improvement in pain at 1 month following therapy initiation (189). Based on the literature, the 2007 Polyanalgesic Consensus Conference Panel recommendations indicate that ziconotide should be considered a Level 1 drug, making it a viable alternative to morphine and hydromorphone (15).

Despite having demonstrated efficacy, ziconotide is associated with several adverse effects. According to an open-label study by Webster et al involving 78 patients receiving IT ziconotide, the most common adverse effects were memory impairment $(11.3 \%)$, dizziness, nystagmus, and speech disorder (8.5\% each), nervousness and somnolence (7\% each), and abnormal gait (5.6\%) (190). However, the researchers concluded that there was no evidence of an increased occurrence of adverse effects at higher cumulative ziconotide doses (190). Other adverse effects reported in clinical trials and case studies include (but are not limited to) elevated creatinine kinase levels, sedation, nausea, headache, lightheadedness, depression, confusion, ataxia, and emotional distress, with certain symptoms possibly correlated with the rate of infusion (15). For patients who experience intolerable adverse effects, ziconotide therapy may be interrupted or discontinued abruptly without producing serious withdrawal symptoms (124).

\subsubsection{Gabapentin.}

The exact mechanism of action of gabapentin is unknown, but it is thought to bind to the $\nabla 2 \otimes$ subunit of voltage-gated calcium channels resulting in the inhibition of glutamate release in the spinal dorsal horn $(191,192)$. It has also been postulated that gabapentin activates the noradrenergic system to produce analgesia following nerve injury $(15,193)$. An experimental drug, IT gabapentin has been shown to reduce neuropathic pain in rat models $(191,194-196)$. For example, a preclinical study comparing the efficacy of IT versus systemic administration of gabapentin in rats found that gabapentin effectively decreased mechanical and cold hypersensitivity, as well as behavioral hypersensitivity, with IT administration superior to systemic administration (191). Additional research has also indicated that gabapentin and tramadol/gabapentin combination therapy can produce a dose-dependent nociceptive effect (192). Another animal study demonstrated that IT gabapentin combined with low-dose morphine decreased pain behaviors in rats and attenuated the development of morphine tolerance (191). Importantly, gabapentin is not yet FDA approved. Clinical studies have been performed but results are unknown.

\subsubsection{Adenosine.}

Adenosine-an endogenous purine nucleosidemodulates many physiologic processes, including those in the heart and CNS. Adenosine has analgesic properties, with the potential to reduce allodynia caused by tissue and peripheral nerve injury $(198,199)$. Acute delivery of adenosine has been found to alleviate pain in patients with neuropathic pain (200-202) and to alleviate nociceptive pain in animal studies (15).

Clinical trials indicate that IT adenosine can be used to effectively treat neuropathic pain in humans $(15,201,202)$. A phase 1 clinical study of bolus IT delivery of adenosine in 12 participants found that the drug reduced the areas of secondary allodynia after skin inflammation and reduced the forearm tourniquet ischemic pain rating (201). Another open-label study evaluated IT adenosine administration in 14 patients with chronic neuropathic pain (eg, tactile hyperalgesia and/or allodynia) (201). In this study, adenosine was associated with a reduction in spontaneous pain (median pain score reduced from 65 to 24 on a 100-point visual analog scale) and evoked pain (median pain score reduced from 71 to 12); in addition, areas of tactile hyperalgesia/allodynia were reduced by a median reduction of $90 \%$ ( $P<.001)$ (201). Despite some demonstrated efficacy, concerns regarding neurotoxicity warrant further investigation before adenosine use can be recommended for widespread use (15).

\subsubsection{Midazolam.}

Midazolam - a benzodiazepine-receptor agonisthas been examined in preclinical and clinical investigations as an adjunctive to IT opioid therapy (15). A study by Canavero et al found that IT midazolam coadministered with clonidine resulted in nearly complete pain relief in 4 patients with chronic noncancer pain, without producing adverse effects or the development of tolerance (203). Studies have shown that IT midazolam/ morphine combination therapy also produces effective pain relief without major adverse events or rapid onset of morphine tolerance $(15,50)$. For example, a pilot 
study of 26 patients with noncancer chronic back and leg pain found that long-term IT midazolam/morphine combination therapy resulted in pain reduction without adverse effects or tolerance (50). However, rat studies have yielded conflicting results with regard to the potential for neurotoxicity with midazolam use (15). Although some experts believe that midazolam is a plausible alternative for intractable chronic pain, others deem a reassessment of safety and toxicity issues is warranted prior to use in humans $(15,159)$. Furthermore, the commercially available formulation available in the United States contains a preservative, and therefore, should not be used in patients with noncancer pain unless they are at end of life (15).

\subsubsection{Cyclooxygenase Inhibitors in IT Therapy.}

Acute pain results in the spinal release of prostaglandins leading to central sensitization (204). The IT delivery of cyclooxygenase (COX) inhibitors reduces pain and hypersensitivity in animals (204). It is, therefore, a reasonable assumption that the IT delivery of COX inhibitors may have a therapeutic effect on a wide range of pain states. A spinal safety assessment of ketorolac in a dog and rat model did not show any toxic effects, and a phase 1 study in healthy volunteers showed no affect on neurologic function or thermal pain thresholds $(205,206)$. There are no clinical studies using IT COX inhibitors to date; yet, from preclinical efficacy and safety studies and clinical safety studies, IT COX inhibitors hold promise for chronic drug delivery.

\subsection{Conclusion}

The consensus panel unanimously agrees that appropriate patient selection is vital to achieving successful outcomes with chronic IT analgesic therapy; however, specific patient selection indications for implantation with an IT drug delivery system are not supported by rigorous, literature-based scientific data. The ultimate determination to proceed with IT therapy requires resolution of 2 principal overlapping decisionswho to implant and when to implant the patient with an internalized device. Although it is challenging to ascertain optimal timing for the initiation of IT therapy, various indicators may signal that a patient is "ready" for this aggressive form of treatment. To optimize clinical practice in the absence of evidence-based guidance or validated tools for chronic IT analgesic therapy patient selection, the panel has assembled a set of arbitrary, multidisciplinary issues that merit consideration during individualized risk-versus-benefit evaluations (Table 13).

By utilizing a multifaceted approach-with consideration of a patient's physical, psychological, and social characteristics-practitioners can determine the appropriateness of initiating IT therapy, thus minimizing the potential for treatment failure, unacceptable adverse effects, and excess mortality.

Related psychological factors influencing patient selection for and appropriate timing of IT therapy initiation can be appraised during an interactive patient interview, a step in the patient selection

Table 13. Key considerations for selection and implantation of patients with noncancer pain for intrathecal therapy

\begin{tabular}{|c|c|}
\hline Contraindications for Immediate Trial/Implant & Indications to Proceed With Trial/Implant \\
\hline $\begin{array}{l}\text { - Immunocompromised patients at high risk for infection or patients } \\
\text { presenting with an active infection }\end{array}$ & - An appropriate diagnosis of the patients pain has been established \\
\hline $\begin{array}{l}\text { - Patients presenting with severe psychological conditions, including } \\
\text { untreated significant addiction; active psychosis with delusional/ } \\
\text { hallucinatory components; major uncontrolled depression/anxiety; } \\
\text { active suicidal or homicidal behavior; serious cognitive deficits; or } \\
\text { severe sleep disturbances }\end{array}$ & $\begin{array}{l}\text { - Chronic pain results in significant interference with activities of daily } \\
\text { living, including ability to work, and overall quality of life }\end{array}$ \\
\hline $\begin{array}{l}\text { - Current or anticipated lack of insurance coverage or means to pay } \\
\text { out-of-pocket for both surgical implantation and ongoing medica- } \\
\text { tion refills/reprogramming }\end{array}$ & $\begin{array}{l}\text { Preexisting medical comorbidities are well-controlled and ap- } \\
\text { propriate disease-specific guidelines are followed pre- and } \\
\text { post-implantation }\end{array}$ \\
\hline \multirow[t]{3}{*}{$\begin{array}{l}\text { - Inability to comply with medication refill schedule due to geo- } \\
\text { graphic limitations }\end{array}$} & $\begin{array}{l}\text { - Patients presenting without any severe or uncontrolled psychological } \\
\text { conditions }\end{array}$ \\
\hline & $\begin{array}{l}\text { - Patient has tried and failed to achieve sufficient analgesia with less } \\
\text { invasive therapies }\end{array}$ \\
\hline & $\begin{array}{l}\text { Patients in which oral opioid therapy is contraindicated (eg, a patient } \\
\text { who has difficulties managing his/her medications, an individual } \\
\text { with certain comorbid conditions in which oral opioids have the } \\
\text { potential for severe adverse effects) }\end{array}$ \\
\hline
\end{tabular}


process that the panel deems crucial to the success of therapy.

\section{Acknowledgments}

Bethany Jones, PharmD, Mary Johnson, Deborah Neveleff, Stacey Ohana, Tiffney Oliver, and Jessica Steuerman are acknowledged for contributions to the planning, research, and medical writing of this article.

We would also like to thank the editorial board of Pain Physician for review and criticism in improving the manuscript.

\section{Disclaimer}

The faculty has reported the following financial relationships with relevant commercial interests: Dr. Deer: Consultant-Codman, Elan, Inset Technologies Inc. Dr. Doleys: Promotional speakers bureau -Medtronic. Dr. Levy: Codman, Medtronic, St. Jude Medical. Dr. Rauck: Grant/research support-Inset Technologies Inc, Medtronic; Consultant-Codman, Elan, Inset Technologies Inc, Medtronic; Promotional speakers bureau-Elan. Dr. Staats: Consultant-ElectroCore; Scientific advisor-ElectroCore; Stock shareholder-ElectroCore; Employee/officer/board member-ElectroCore. Dr. Wallace: Grant/research support-Medtronic; Scientific advisorElan. Dr. Webster: Consultant-Ameritox, Boston Scientific, Cephalon, Corona Productions, Elan, King Pharmaceuticals, MediCom Worldwide, Medtronic, Medscape; Research/grant support-Abbott, Advanced Bionic, Ameritox, Arrya, AstraZeneca, Boehringer Ingelheim, cervelo, CoMentis, Durect, Elan, Elite, Forest, GlaxoSmithKline, Jazz Pharmaceuticals, Inc, King Pharmaceuticals, Medtronic, Merck \& Co, Inc, Nektar, NeurogesX, Pain Therapeutics, Inc, Purdue, QRxPharma, Respironics, Takeda Pharmaceutical North America, TorreyPines, Wyeth, Zars; Scientific advisor-Ameritox, King Pharmaceuticals, Nektar, Nervo, Neuromed,

Purdue, QRxPharma. Dr. Cousins, Dr. Rathmell, and Dr. Smith disclosed no relevant financial relationships with any commercial interests

\section{References}

1. Manchikanti L, Singh V, Helm S, Schultz DM, Datta S, Hirsch J. An introduc tion to an evidence-based approach to interventional techniques in the management of chronic spinal pain. Pain Physician 2009; 12:E1-E33.

2. Freburger J, Holmes G, Agans R, Jackman A, Darter J, Wallace A, Castel L, Kalsbeek W, Carey T. The rising prevalence of chronic low back pain. Arch Intern Med 2009; 169:251-258.

3. Manchikanti L, Boswell MV, Singh V, Benyamin RM, Fellows B, Abdi S, Buenaventura RM, Conn A, Datta S, Derby R, Falco FJE, Erhart S, Diwan S, Hayek SM, Helm S, Parr AT, Schultz DM, Smith HS, Wolfer LR, Hirsch JA. Comprehensive evidence-based guidelines for interventional techniques in the management of chronic spinal pain. Pain Physician 2009; 12:699-802.

4. Manchikanti L. Singh V, Datta S, Cohen SP, Hirsch JA. Comprehensive review of epidemiology, scope, and impact of spinal pain. Pain Physician 2009; 12: E35-E70.

5. Manchikanti L, Boswell MV, Singh V, Derby R, Fellows B, Falco FJE, Datta S, Smith HS, Hirsch JA. Comprehensive review of neurophysiologic basis and diagnostic interventions in managing chronic spinal pain. Pain Physician 2009; 12:E71-E120.

6. Manchikanti L, Boswell MV, Datta S, Fel- lows B, Abdi S, Singh V, Benyamin RM, Falco FJE, Helm S, Hayek S, Smith HS. Comprehensive review of therapeutic interventions in managing chronic spinal pain. Pain Physician 2009: 12:E123E198.

7. Manchikanti L, Singh V, Pampati V, Boswell MV, Benyamin RM, Hirsch JA. Description of documentation in the management of chronic spinal pain. Pain Physician 2009: 12:E199-E224.

8. Manchikanti L, Helm S, Singh V, Benyamin RM, Datta S, Hayek S, Fellows B, Boswell MV. An algorithmic approach for clinical management of chronic spinal pain. Pain Physician 2009; 12:E225E264.

9. Giordano J, Schatman ME, Höver G. Eth ical insights to rapprochement in pain care: bringing stakeholders together in the best interest(s) of the patient. Pain Physician 2009; 12:E265-E275.

10. Deer TR. An overview of interventional spinal techniques. Semin Pain Med 2004;2:154-66.

11. Patel VB, Manchikanti L, Singh V, Schultz DM, Hayek SM, Smith HS. Systematic review of intrathecal infusion systems for long-term management of chronic non-cancer pain. Pain Physician 2009; 12:345-360.

12. Wallace M, Yaksh TL. Long-term spinal analgesic delivery: a review of the preclinical and clinical literature. Reg
Anesth Pain Med 2000;25:117-57.

13. Krames ES. Intraspinal opioid therapy for chronic nonmalignant pain: current practice and clinical guidelines. J Pain Symptom Manage 1996;11:333-52.

14. Implantable Infusion Pumps for Chronic Noncancer Pain. Health Technology Assessment. Washington State Health Care Authority; July 18, 2008. www.hta. hca.wa.gov/documents/implantable infusion_pumps_final.pdf

15. Deer T, Krames ES, Hassenbusch SJ, et al. Polyanalgesic Consensus Conference 2007: recommendations for the management of pain by intrathecal (intraspinal) drug delivery: report of an interdisciplinary expert panel. Neuromodulation 2007;10:300-28.

16. Manchikanti L, Singh V, Helm S, Schultz DM, Datta S, Hirsch J. An introduction to an evidence-based approach to interventional techniques in the management of chronic spinal pain. Pain Physician 2009; 12:E1-E33.

17. Sniderman $A D$, Furberg $C D$. Why guideline-making requires reform. JAMA 2009; 301:429-431.

18. Eden J, Wheatley B, McNeil B, Sox H. Developing trusted clinical practice guidelines. In Knowing What Works in Health Care: A Roadmap for the Nation. National Academies Press, 2008, Washington, DC, pp 121-152.

19. Manchikanti L. Evidence-based med- 
icine, systematic reviews, and guidelines in interventional pain management: Part 1: Introduction and general considerations. Pain Physician 2008; 11:161-186.

20. Manchikanti L, Hirsch JA, Smith HS. Evidence-based medicine, systematic reviews, and guidelines in interventional pain management: Part 2: Randomized controlled trials. Pain Physician 2008; 11:717-773.

21. Manchikanti L, Smith HS, Hirsch JA. Evidence-based medicine, systematic reviews, and guidelines in interventional pain management: Part 3: Systematic reviews and meta-analysis of randomized trials. Pain Physician 2009; 12:3572.

22. Manchikanti L, Smith HS, Hirsch JA. Evidence-based medicine, systematic reviews, and guidelines in interventional pain management: Part 4: Observational studies. Pain Physician 2009; 12:73-108.

23. Singh V, Manchikanti L, Shah RV, Dunbar EE, Glaser SE. Systematic review of thoracic discography as a diagnostic test for chronic spinal pain. Pain Physician 2008; 11:631-642.

24. Conn A, Buenaventura R, Datta S, Abdi S, Diwan S. Systematic review of caudal epidural injections in the management of chronic low back pain. Pain Physician 2009; 12:109-135.

25. Parr AT, Diwan S, Abdi S. Lumbar interlaminar epidural injections in managing chronic low back and lower extremity pain: A systematic review. Pain Physician 2009; 12:163-188.

26. Benyamin RM, Singh V, Parr AT, Conn A, Diwan S, Abdi S. Systematic review of the effectiveness of cervical epidurals in the management of chronic neck pain. Pain Physician 2009; 12:137-157.

27. Buenaventura R, Datta S, Abdi S, Smith HS. Systematic review of therapeutic lumbar transforaminal epidural steroid injections. Pain Physician 2009; 12:233-251.

28. Helm S, Hayek S, Benyamin RM, Manchikanti L. Systematic review of the effectiveness of thermal annular procedures in treating discogenic low back pain. Pain Physician 2009; 12:207-232.

29. Manchikanti L, Dunbar EE, Wargo BW, Shah RV, Derby R, Cohen SP. Systematic review of cervical discography as a diagnostic test for chronic spinal pain. Pain Physician 2009; 12:305-321.
30. Datta S, Lee M, Falco FJE, Bryce DA, Hayek SM. Systematic assessment of diagnostic accuracy and therapeutic utility of lumbar facet joint interventions. Pain Physician 2009; 12:437460.

31. Falco FJE, Erhart S, Wargo BW, Bryce DA, Atluri S, Datta S, Hayek SM. Systematic review of diagnostic utility and therapeutic effectiveness of cervical facet joint interventions. Pain Physician 2009; 12:323-344.

32. Frey ME, Manchikanti L, Benyamin RM, Schultz DM, Smith HS. Spinal cord stimulation for patients with failed back surgery syndrome: A systematic review. Pain Physician 2009; 379-397.

33. Epter RS, Helm S, Hayek SM, Benyamin RM, Smith HS, Abdi S. Systematic review of percutaneous adhesiolysis and management of chronic low back pain in post lumbar surgery syndrome. Pain Physician 2009; 12:361-378.

34. Smith HS, Chopra P, Patel VB, Frey ME, Rastogi R. Systematic review on the role of sedation in diagnostic spinal interventional techniques. Pain Physician 2009; 12:195-206.

35. Rupert MP, Lee M, Manchikanti L, Datta S, Cohen SP. Evaluation of sacroiliac joint interventions: A systematic appraisal of the literature. Pain Physician 2009; 12:399-418.

36. Manchikanti L, Glaser S, Wolfer L, Derby $\mathrm{R}$, Cohen SP. Systematic review of lumbar discography as a diagnostic test for chronic low back pain. Pain Physician 2009; 12:541-559.

37. Hayek SM, Helm S, Benyamin RM, Singh V, Bryce DA, Smith HS. Effectiveness of spinal endoscopic adhesiolysis in post lumbar surgery syndrome: A systematic review. Pain Physician 2009; 12:419435 .

38. Trescot AM, Helm S, Hansen H, Benyamin RM, Adlaka R, Patel S, Manchikanti L. Opioids in the management of chronic non-cancer pain: An update of American Society of Interventional Pain Physicians' (ASIPP) guidelines. Pain Physician 2008; 11:S5-S62.

39. Manchikanti L, Singh V, Derby R, Schultz DM, Benyamin RM, Prager JP, Hirsch JA. Reassessment of evidence synthesis of occupational medicine practice guidelines for interventional pain management. Pain Physician 2008; 11:393482.

40. Manchikanti L, Singh V, Derby R, Helm S, Trescot AM, Staats PS, Prager JP,
Hirsch JA. Review of occupational medicine practice guidelines for interventional pain management and potential implications. Pain Physician 2008; 11:271-289.

41. Manchikanti L, Singh V, Helm S, Trescot AM, Hirsch JA. A critical appraisal of 2007 American College of Occupational and Environmental Medicine (ACOEM) practice guidelines for interventional pain management: An independent review utilizing AGREE, AMA, IOM, and other criteria. Pain Physician 2008; 11:291-310.

42. Hassenbusch SJ, Stanton-Hicks MD, Soukup J, Covington EC, Boland MB. Sufentanil citrate and morphine/bupivacaine as alternative agents in chronic epidural infusions for intractable noncancer pain. Neurosurgery 1991;29:7682.

43. Angel IF, Gould HJ Jr, Carey ME. Intrathecal morphine pump as a treatment option in chronic pain of nonmalignant origin. Surg Neurol 1998;49:92-8.

44. Anderson VC, Burchiel KJ. A prospective study of long-term intrathecal morphine in the management of chronic nonmalignant pain. Neurosurgery 1999;44:289-300.

45. Kumar K, Kelly M, Pirlot T. Continuous intrathecal morphine treatment for chronic pain of nonmalignant etiology: long-term benefits and efficacy. Surg Neurol 2001;55:79-88.

46. Thimineur MA, Kravitz E, Vodapally MS. Intrathecal opioid treatment for chronic non-malignant pain: a 3-year prospective study. Pain 2004;109:242-9.

47. Deer T, Chapple I, Classen A, Javery K, Stoker V, Tonder L, Burchiel K.. Intrathecal drug delivery for treatment of chronic low back pain: report from the National Outcomes Registry for Low Back Pain. Pain Med 2004;5:6-13.

48. Winkelmüller $M$, Winkelmüller W. Longterm effects of continuous intrathecal opioid treatment in chronic pain of nonmalignant etiology. J Neurosurg 1996;85:458-67.

49. Paice JA, Penn RD, Shott S. Intraspinal morphine for chronic pain: a retrospective, multicenter study. J Pain Symptom Manage 1996;11:71-80.

50. Rainov NG, Heidecke V, Burkert W. Longterm intrathecal infusion of drug combinations for chronic back and leg pain. J Pain Symptom Manage 2001;22:86271.

51. Deer TR, Caraway DL, Kim CK, Dempsey 
CD, Stewart CD, McNeil KF. Clinical experience with intrathecal bupivacaine in combination with opioid for the treatment of chronic pain related to failed back surgery syndrome and metastatic cancer pain of the spine. Spine J 2002;2:274-8.

52. Mironer YE, Haasis JC, Chapple I, Brown C, Satterthwaite JR. Efficacy and safety of intrathecal opioid/bupivacaine mixture in chronic nonmalignant pain: a double blind, randomized, crossover, multicenter study by the National Forum of Independent Pain Clinicians (NFIPC). Neuromodulation 2002;5:20813.

53. Ackerman LL, Follett KA, Rosenquist RW. Long-term outcomes during treatment of chronic pain with intrathecal clonidine or clonidine/opioid combinations. J Pain Symptom Manage 2003;26:668-77.

54 .Staats PS, Yearwood T, Charapata SG, Presley RW, Wallace MS, Byas-Smith M, Fisher R, Bryce DA, Mangieri EA, Luther RR, Mayo M, McGuire D, Ellis D.. Intrathecal ziconotide in the treatment of refractory pain in patients with cancer or AIDS: a randomized controlled trial. JAMA 2004;291:63-70.

55. Wallace MS, Kosek PS, Staats P, Fisher R, Schultz DM, Leong M. Phase II, openlabel, multicenter study of combined intrathecal morphine and ziconotide: addition of ziconotide in patients receiving intrathecal morphine for severe chronic pain. Pain Med 2008;9:271-81.

56. Turner JA, Sears JM, Loeser JD. Programmable intrathecal opioid delivery systems for chronic noncancer pain: a systematic review of effectiveness and complications. Clin J Pain 2007;23:18095.

57. Noble M, Tregear SJ, Treadwell JR, Schoelles K. Long-term opioid therapy for chronic noncancer pain: a systematic review and meta-analysis of efficacy and safety. J Pain Symptom Manage 2008;35:214-28.

58. Moulin DE, lezzi A, Amireh R, Sharpe WK, Boyd D, Merskey H. Randomised trial of oral morphine for chronic noncancer pain. Lancet 1996;347:143-7.

59. Molloy AR, Nicholas MK, Asghari A, Beeston L, Dehghani M, Cousins M, Brooker C, Tonkin L. Does a combination of intensive cognitive-behavioral pain management and a spinal implantable device confer any advantage? A preliminary examination. Pain
Pract 2006;6:96-103.

60. Cohen SP, Dragovich A. Intrathecal analgesia. Anesthesiology Clin 2007;25:863-82.

61. Smith HS, Deer TR, Staats PS, Singh V, Sehgal N, Cordner H. Intrathecal drug delivery. Pain Physician 2008;11:S89S104.

62. Ghafoor VL, Epshteyn M, Carlson GH, Terhaar DM, Charry O, Phelps PK. Intrathecal drug therapy for long-term pain management. Am J Health Syst Pharm 2007;64:2447-61.

63. Roberts LJ, Finch PM, Pullan PT, Bhagat $\mathrm{Cl}$, Price LM. Sex hormone suppression by intrathecal opioids: a prospective study. Clin J Pain 2002;18:144-8.

64. Daniell HW. Opioid endocrinopathy in women consuming prescribed sustained-action opioids for control of nonmalignant pain. J Pain 2008;9:2836.

65. Belverud S, Mogilner A, Schulder M. Intrathecal pumps. Neurotherapeutics 2008;5:114-22.

66. Rathmell JP, Miller MJ. Death after initiation of intrathecal drug therapy for chronic pain: assessing risk and designing prevention. Anesthesiology 2009. (In press.)

67. Plummer JL, Cmielewski PL, Gourlay GK, Owen H, Cousins MJ. Antinociceptive and motor effects of intrathecal morphine combined with intrathecal clonidine, noradrenaline, carbachol or midazolam in rats. Pain 1992;49:14552.

68. Siddall PJ, Molloy AR, Walker S, Mather LE, Rutkowski SB, Cousins MJ. The efficacy of intrathecal morphine and clonidine in the treatment of pain after spinal cord injury. Anesth Analg 2000;91:1493-8.

69. Walker SM, Goudas LC, Cousins MJ, Carr DB. Combination spinal analgesic chemotherapy: a systematic review. Anesth Analg 2002;95:674-715.

70. Jones RL, Rawlins PK. The diagnosis of intrathecal infusion pump system failure. Pain Physician 2005;8:291-6.

71. Fitzgibbon D, Rapp S, Butler S, Terman G, Dolack G, DuPen S, Ready B. Rebound hypertension and withdrawal associated with discontinuation of an infusion of epidural clonidine. Anesthesiology 1996;84:729-731.

72. Deer TR, Krames E, Levy RM, Hassenbusch SJ, Prager JP. Practice choices and challenges in the current intrathe- cal therapy environment: an online survey. Pain Med 2009;10:304-9.

73. Hassenbusch S, Burchiel K, Coffey RJ, et al. Management of intrathecal catheter-tip inflammatory masses: a consensus statement. Pain Med 2002;3:31323.

74. Deer T, Winkelmuller W, Erdine S, Bed$\operatorname{der} M$, Burchiel K. Intrathecal therapy for cancer and nonmalignant pain: patient selection and patient management. Neuromodulation 1999;2:55-66.

75. Sinatra R. Opioid analgesics in primary care: challenges and new advances in the management of noncancer pain. J Am Board Fam Med 2006;19:165-77.

76. Di Bari M, Virgillo A, Matteuzzi D, Inzitari M, Mazzaglia G, Pozzi C, Geppetti P, Masotti G, Marchionni N, Pini R. Predictive validity of measures of comorbidity in older community dwellers: the Insufficienza Cardiaca negli Anziani Residenti a Dicomano Study. J Am Geriatr Soc 2006;54:210-216

77. Rozzini R, Frisoni GB, Ferrucci L, Barbisoni P, Sabatini T, Ranieri P, Guralnik J, Trabucchi M. Geriatric Index of Comorbidity: validation and comparison with other measures of comorbidity. Age Ageing 2002;31:277-285.

78. Centers for Disease Control and Prevention. National diabetes fact sheet, 2007. www.cdc.gov/diabetes/pubs/ pdf/ndfs_2007.pdf. Accessed August 11, 2009.

79. American Diabetes Association. All about diabetes. www.diabetes.org/ about-diabetes.jsp. Accessed July 28, 2009.

80. National Diabetes Information Clearinghouse (NDIC). Diabetic neuropathies: the nerve damage of diabetes. http://diabetes.niddk.nih.gov/dm/ pubs/neuropathies/index.htm. Accessed July 28, 2009.

81. Krein SL, Heisler M, Piette JD, Makki F, Kerr EA. The effect of chronic pain on diabetes patients, self-management. Diabetes Care 2005;28:65-70.

82. Greenhalgh DG. Wound healing and diabetes mellitus. Clin Plast Surg 2003; 30:37-45.

83. Follet KA, Boortz-Marx RL, Drake JM, DuPen S, Schneider S, Turner M, Coffey $R$. Prevention and management of intrathecal drug delivery and spinal cord stimulation system infections. Anesthesiology 2004;100:1582-1594.

84. Van den Berghe G. How does blood 
glucose control with insulin save lives in intensive care? J Clin Invest 2004; 114:1187-1195.

85. Rathmell JP, Lake T, Ramundo MB. Infectious risks of chronic pain treatments: injection therapy, surgical implants, and intradiscal techniques. Reg Anesth Pain Med 2006; 31:346-352.

86. Horlocker TT, Wedel DJ, Benzon H, et al. Regional anesthesia in the anticoagulated patient: defining the risks (the Second ASRA Consensus Confererence on Neuraxial Anesthesia and Anticoagulation). Reg Anesth Pain Med 2003; 28:172-97.

87. Chaney MA. Intrathecal and epidural anesthesia and analgesia for cardiac surgery. Anesth Analg 2006; 102:45 64.

88. Knight KH, Brand FM, Mchaourab AS, Veneziano G. Implantable intrathecal pumps for chronic pain: highlights and updates. Croat Med J 2007;48:22-34

89. The Joint Commission. Preventing errors relating to commonly used anticoagulants. www.jointcommission.org/ SentinelEvents/SentinelEventAlert/ sea_41.htm. Accessed July 28, 2009.

90. Risdahl JM, Khanna KV, Peterson PK, Molitor TW. Opioids and infection. Neuroimmunol 1998;83:4-18.

91. Smith TJ, Staats PS, Deer T, Stearns L, Rauck R, Boortz-Marx R, Buchser E, Catala E, Bruce D, Coyne P, Pool G. Randomized clinical trial of an implantable drug delivery system compared with comprehensive medical management for refractory cancer pain: Impact on pain, drug-related toxicity, and survival. J Clin Oncol 2002;20:4040-4049.

92. Stearns L, Boortz-Marx R, Du Pen S, Friehs G, Gordon M, Halyard M, Herbst L, Kiser J. Intrathecal drug delivery for the management of cancer pain: a multidisciplinary consensus of best clinical practices. J Support Oncol 2005;3:399408.

93. Ogden $\mathrm{CL}$, Carrol MD, McDowell MA, Flegal KM. Obesity among adults in the United States-No statistically significant change since 2003-2004. NCHS Data Brief 2007;1:1-6.

94. National Sleep Foundation. Obstructive sleep apnea and sleep. www.sleep foundation.org/article/sleep-related problems/obstructive-sleep-apneaand-sleep. Accessed August 11, 2009.

95. Farney RJ, Walker JM, Cloward TV, Rhondeau S. Sleep-disordered breathing associated with long-term opioid therapy.
Chest 2003;123:632-9.

96. Webster LR, Choi Y, Desai H, Webster L, Grant B. Sleep-disordered breathing and chronic opioid therapy. Pain Med 2008;9:425-432.

97. Horlocker TT, Burton AW, Connis RT, Hughes S, Nickinovich D, Palmer C, Pollock J, Rathmell J, Rosenquist R, Swisher J, Wu C. Practice guidelines for the prevention, detection, and management of respiratory depression associated with neuraxial opioid administration. Anesthesiology 2009;110:218230.

98. Smith HS, Deer TR. Safety and efficacy of intrathecal ziconotide in the management of severe chronic pain. Ther Clin Risk Manage 2009;5:521-534.

99. American Lung Association. Data and statistics. www.lungusa.org/site/pp.as $p ? c=d v L U K 9 O \circ E \& b=33347$. Accessed July $28,2009$.

100. Taylor S, Kirton OC, Staff I, Kozol RA. Postoperative day one: A high risk period for respiratory events. Am J Surg 2005;190:752-6.

101. American College of Cardiology/American Heart Association Task Force. ACC/ AHA 2007 Guidelines for perioperative cardiovascular evaluation and care for noncardiac surgery: executive summary: A report of the American College of Cardiology/American Heart Association Task Force on Practice Guidelines/ Writing Committee to Revise the 2002 Guidelines on Perioperative Cardiovascular Evaluation for Surgery. Anesth Analg 2008;106:685-712.

102. National Kidney and Urologic Diseases Information Clearinghouse (NKUDIC). Kidney and urologic diseases statistics for the United States. www.kidney.niddk.nih.gov/kudiseases/pubs/kustats/ index.htm. Accessed July 28, 2009.

103. Hage FG, Venkataraman R, Zoghbi GJ, Perry G, DeMattos A, Iskandrian A. The scope of coronary heart disease in patients with chronic kidney disease. J Am Coll Cardiol 2009;53:2129-2140.

104. Pergolizzi J, Boger RH, Budd K, Dahan A, Evdine S, Hans G, Kress HG, Langford R, Likar R, Raffa R, Sacerdote P. Opioids and the management of chronic severe pain in the elderly: consensus statement of an international expert panel with focus on the six clinically most often used World Health Organization step III opioids (buprenorphine, fentanyl, hydromorphine, methadone, morphine, oxycodone). Pain
Pract 2008;8:287-313.

105. Buntin-Mushock C, Phillip L, Moriyama K, Pierce PP. Age-dependent opioid escalation in chronic pain patients. Anesth Analg 2005; 100:1740-1745.

106. Webster LR, Webster RM. Predicting aberrant behaviors in opioid-treated patients: Preliminary validation of the opioid risk tool. Pain Med 2005; 6:432442.

107. Doleys, DM. Psychological evaluation for patients undergoing implantable technology. In Krames E, Peckman PH, and Rezai A, eds. Textbook of Neuromodulation. Oxford, England: Blackwell Publishing Co, 2009; pp. 69-80.

108. Burton AW, Conroy B, Garcia E, Solanki D, Williams CGA. Illicit substance abuse via an implanted intrathecal pump. Anesthesiology 1998; 89:1264-1267,.

109. Doleys DM. Preparing patients for implantable technology. In: Turk DC, Gatchel RJ, eds. Psychological Approaches to Pain Management. New York, NY: The Guilford Press, 2002:334348.

110. Doleys DM. Psychologic evaluation for patients undergoing neuroaugmentative procedures. Neurosurg Clin N Am 2003; 14:409-417.

111. Nelson DV, Kennington M, Novy DM, Squitieri P. Psychological selection criteria for implanatable spinal cord stimulators. Pain Forum 1996; 5:93-103.

112. Celestin J, Edwards RR, Jamison RN. Pretreatment psychosocial variables as predictors of outcomes following lumbar surgery and spinal cord stimulation: a systematic review and literature synthesis. Pain Med 2009; 10:639653.

113. Doleys DM, Brown J. MMPI profiles as an outcome 'predictor' in the treatment of non-cancer pain patients utilizing intraspinal opioid therapy. Neuromodulation 2001; 4:93-97.

114. Doleys DM, Klapow J, Hammer M. Psychological evaluation in spinal cord stimulation. Pain Reviews 1997;4:186204.

115. Doleys DM, Olson K, eds. Psychological assessment and intervention in Implantable Pain Therapies (Monograph). Minneapolis: Medtronic Neurological 1997; pp 1-20.

116. Doleys DM, Coleton M, Tutak U. Use of intraspinal infusion therapy for noncancer pain patients: Follow-up and comparison of worker's compensation versus non-worker's compensation pa- 
tients. Neuromodulation 1998;1:14959.

117. Willis KD, Doleys DM. The effects of long term intraspinal infusion therapy with non-cancer pain patients: Evaluation of patient, significant-other and clinic staff appraisals. Neuromodulation 1999; 2:241-253.

118. Doleys DM, Kraus TJ. Trialing for intrathecal therapy: comments and considerations. Practical Pain Management 2007; 7:48-49.

119. Follett KA, Doleys DM. Selection of Candidates for Intrathecal Drug Adminis tration to Treat Chronic Pain: Considerations in Pre-Implantation Trials. Minneapolis: Medtronic Inc, 2004:1-19.

120. Williams DA, Epstein SA. Psychological assessment prior to surgery for implantable pain-management devices. In Burchiel K, ed. Surgical Management of Pain. New York: Thieme Medical, 2002:135-44.

121. Prager J, Jacobs M. Evaluation of patients for implantable pain modalities: Medical and behavioral assessment. Clin J Pain 2001; 17:206-214.

122. Wilson PR, Caplan RA, Connis RT, Gilbert HC, Grigsby EJ, Haddox JD, Harvey AM, Korevaar WC, Lubenow TR, Simon DL. Practice guidelines for chronic pain management. Anesthesiology 1997;86:995-1004.

123. Rauck RL, Wallace MS, Leong MS, MineHart M, Wesbster L, Charapata S, Abraham J, Buffington D, Ellis D, Kartzinel R. A randomized, double-blind, placebo-controlled study of intrathecal ziconotide in adults with severe chronic pain. J Pain Symptom Manage 2006;31:393-406.

124. Wallace MS, Charapata SG, Fisher R, Byas-Smith M, Staats P, Mayo M, McGuire d, Ellis D. Intrathecal ziconotide in the treatment of chronic nonmalignant pain: a randomized, double-blind, placebo-controlled clinical trial. Neuromodulation 2006;9:75-86.

125. Webster LR, Fakata KL, Charapata S, Fisher R, MineHart M. Open-label, multicenter study of combined intrathecal morphine and ziconotide: addition of morphine in patients receiving ziconotide for severe chronic pain. Pain Med 2008;9:282-90.

126. Prager JP. Neuraxial medication delivery: The development and maturity of a concept for treating chronic pain of spinal origin. Spine (Phila PA 1976)
2002;27:2593-605.

127. Furlan AD, Sandoval JA, Mailis-Gagnon A, Tunks E. Opioids for chronic noncancer pain: a meta-analysis of effectiveness and side effects. CMAJ 2006;174:1589-94.

128. Morley-Forster PK, Clark AJ, Speechley M, Moulin DE. Attitudes toward opioid use for chronic pain: a Canadian physician survey. Pain Res Manag 2003;8:189-94.

129. Kalso E, Edwards JE, Moore RA, McQuay HJ. Opioids in chronic non-cancer pain: systematic review of efficacy and safety. Pain 2004; 112:372-80.

130. Ballantyne JC, Mao J. Opioid therapy for chronic pain. N Engl J Med 2003; 349:1943-53.

131. Palangio M, Morris E, Doyle RT Jr, Dornseif BE, Valente TJ. Combination hydrocodone and ibuprofen versus combination oxycodone and acetaminophen in the treatment of moderate or severe acute low back pain. Clin Ther 2002; 24:87-99.

132. Allan L, Richarz U, Simpson K, Slappendel R. Transdermal fentanyl versus sustained release oral morphine in strong. opioid naïve patients with chronic low back pain. Spine (Phila Pa 1976) 2005; 30:2484-2490.

133. Argoff CE, Silvershein DI. A comparison of long- and short-acting opioids for the treatment of chronic noncancer pain: Tailoring therapy to meet patient needs. Mayo Clin Proc 2009;84:602612.

134. Onofrio BM, Yaksh TL. Long-term pain relief produced by intrathecal morphine infusion in 53 patients. J Neurosurg1990;72:200-9.

135. Onofrio BM, Yaksh TL, Arnold PG. Continuous low-dose intrathecal morphine administration in the treatment of chronic pain of malignant origin. Mayo Clin Proc 1981;56:516-20.

136. Yaksh TL, Reddy SV. Studies in the primate on the analgetic effects associated with intrathecal actions of opiates, alpha-adrenergic agonists and baclofen. Anesthesiology 1981; 54:451467.

137. Deer T, Ranson M, Stewart D. Relevant anatomy for spinal delivery. In Krames E, Hunter Peckham P, Rezai A, eds. Neuromodulation New York, NY: Elsevier, 2009.

138. Follett KA, Burchiel K, Deer T, DuPen S, Prager J, Turner M, Coffey R. Prevention of intrathecal drug delivery catheter-re- lated complications. Neuromodulation 2003;6:32-41.

139. Coffey RJ, Owens ML, Broste SK, Dubois $M$, Ferrante M, Schultz D, Stearns L, Turner M. Mortality associated with implantation and management of intrathecal opioid drug infusion systems to treat noncancer pain. Anesthesiology 2009. (In press.)

140. Carr DB, Cousins MJ. Spinal route of analgesia: Opioids and future options for spinal analgesic chemotherapy. In: Cousins MJ, Carr DB, Horlocker TT, Bridenbaugh PO, eds. Neural Blockade in Clinical Anesthesia and Pain Medicine, 4th ed. Wolters Kluwer Lippincott Williams \& Wilkins, 2008: 886-947.

141. The American Pain Foundation. Pain facts and figures. www.painfoundation. org/print.asp?file=Newsroom $/$ PainFacts.htm. Accessed August 4, 2009.

142. Brennan F, Carr DB, Cousins M. Pain management: A fundamental human right. Anesth Analg 2007; 105:205-21.

143. Bedder MD, Burchiel K, Larson A. Cost analysis of two implatable narcotic delivery systems. I Pain Symptom Manage 1991; 6:368-373.

144. De Lissovoy G, Brown RE, Halpern M, Hassenbusch SJ, Ross E. Cost-effectiveness of long-term intrathecal morphine therapy for pain associated with failed back surgery syndrome. Clin Ther 1997;19:96-111.

145. Kumar K, Hunter G, Demeria DD. Treatment of chronic pain by using intrathecal drug therapy compared with conventional pain therapies: a cost-effectiveness analysis. J Neurosurg 2002; 97:803-810.

146. Prescription Price Center (2009). www. drugstore.com/pharmacy/drugindex. Accessed April 3, 2009.

147. Medtronic for Healthcare Professionals. Intrathecal drug delivery for chronic pain: physician commonly billed codes (January 2009). http://professional.medtronic.com/downloads/ idd/idd-physician-common-codes.pdf. Accessed April 15, 2009.

148. Medtronic for Healthcare Professionals. Intrathecal drug Delivery for chronic pain: hospital commonly billed codes. (January 2009). http://professional. medtronic.com/downloads/idd/iddhospital-common-codes.pdf. Accessed April 15, 2009.

149. Centers for Medicare \& Medicaid Services. Medicare Part B drug average sales price. 2009 ASP drug pricing files. 
www.cms.hhs.gov/McrPartBDrugAvgSalesPrice. Accessed April 21, 2009.

150. Federal Register. Hospital outpatient rates. Volume 73, Number 193, October 3, 2008.

151. Federal Register. Physician rates. Volume 73, Number 224, November 19 , 2008.

152. Ilias W, Todoroff B. Optimizing pain control through the use of implantable pumps. Medical Devices: Evidence and Research 2008;1:41-7.

153. Infumorph [package insert]. Deerfield, IL: Baxter Healthcare Corporation; 2004 .

154. Astramorph [package insert]. Wilmington, DE: AstraZeneca; 2005.

155. Prialt [package insert]. San Diego, CA: Elan Pharmaceuticals, Inc; 2006.

156. Baxter DW, Schacherl U. Experimental studies on the morphological changes produced by intrathecal phenol. Can Med Assoc J 1962;86:1200-5.

157. Hetherington NJ, Dooley MJ. Potential for patient harm from intrathecal administration of preserved solutions. Med J Aust 2000;173:141-3.

158. Medtronic Educational Brief. October 2002/2.03a. MHRA Medical Device Alert 2003/007/023/121/003, issued October 2003.

159. Jones TF, Feler CA, Simmons BP, et al. Neurologic complications including $\mathrm{pa}$ ralysis after a medication error involving implanted intrathecal catheters. Am J Med 2002;112:31-6.

160. Yaksh TL, Allen JW. The use of intrathecal midazolam in humans: a case study of process. Anesth Analg 2004;98:153645.

161. Hassenbusch SJ, Portenoy RK, Cousins $\mathrm{M}$, et al. Polyanalgesic Consensus Conference 2003: an update on the management of pain by intraspinal drug delivery-report of an expert panel. J Pain Symptom Manage 2004;27:540-63.

162. Ubogu EE, Lindenberg JR, Werz MA. Transverse myelitis associated with Acinetobacter baumanii intrathecal pump catheter-related infection. Reg Anesth Pain Med 2003;28:470-4.

163. Breaux PJ. Application of federal law to compounding of prescription orders. La State Med Soc 1998;150:275-8.

164. Crawford LM Jr. From the Food and Drug Administration: pharmacy compounding guidance. JAMA 2002;288:1579.

165. Thompson CA. USP publishes en- forceable chapter on sterile compounding. Am J Health Syst Pharm 2003;60:1814,1817-8,1822.

166. American Society of Health-System Pharmacists (ASHP). ASHP guidelines on quality assurance for pharmacy-prepared sterile products. Am J Health Syst Pharm 2000; 57:1150-69.

167 Hung JC. USP general chapter 797 ; * Pharmaceutical compounding-sterile preparations. J Nucl Med 2004;45:20N, $28 \mathrm{~N}$.

168. US Pharmacopeia (USP). USP General Chapter $797 \cdots$, Pharmaceutical Compounding-Sterile Preparations. Official revision, June 1, 2008.

169. Caraway D, Saulino M, Fisher R. Interventional therapy: intrathecal therapy trials with ziconotide. Practical Pain Management March 2008.

170. Levy RM. Quantitative, crossover, double-blind trial paradigm for patient screening for chronic intraspinal narcotic administration. Neurosurgical Focus 1997;2:e2. javascript:PopUpMenu2_Set(Menu15096023);

171. Dominguez E, Sahinler B, Bassam D, Day M, Lou L, Racz G, Raj P. Predictive value of intrathecal narcotic trials for long-term therapy with implantable drug administration systems in chronic non-cancer pain patients. Pain Pract 2002; 2:315--325.

172. Hassenbusch SJ, Stanton-Hicks M, Covington EC, Walsh JG, Guthrey DS. Longterm intraspinal infusions of opioids in the treatment of neuropathic pain. J Pain Symptom Manage 1995;10:52743.

173. Yoshida GM, Nelson RW, Capen DA, Nagelberg S, Thomas JC, Rimoldi RL, Haye W. Evaluation of continuous intraspinal narcotic analgesia for chronic pain from benign causes. Am J Orthop 1996; 25:693-694.

174. Follett KA, Doleys DM. Selection of candidates for intrathecal drug administration to treat chronic pain: considerations in pre-implantation Trials. Minneapolis, MN: Medtronic, Inc, 2002.

175. Medicare Coverage Issues Manual. Coverage issues-durable medical equipment. www.cms.hhs.gov/manuals/downloads/Pubo6_PART_6o.pdf. Accessed August 19, 2009.

176. Quang-Cantagrel ND, Wallace MS, Magnuson SK. Opioid substitution to improve the effectiveness of chronic noncancer pain control: a chart review.
Anesth Analg 2000;90:933-7.

177. Krames ES. Intraspinal analgesia for nonmalignant pain. In: Waldman SD, ed. Interventional Pain Management. 2nd ed. Philadelphia, PA: W.B. Saunders Company, 2001:609-619.

178. Manfredi PL, Chandler SW, Patt R, Payne R. High-dose epidural infusion of opioids for cancer pain: cost issues. J Pain Symptom Manage 1997;13:11821.

179. InSet Technologies. Information on file with the company.

180. Clinical Trials. Prometra implantable programmable pump (PUMP). http://clinicaltrials.gov/ct2/show/ NCToo817596. Accessed May 08, 2009.

181. Clinical Trials. Prometra's utilization in mitigating pain II (PUMP2). http://clinicaltrials.gov/ct2/show/NCT00866164. Accessed May 08, 2009.

182. Rosen S, Deer T, Rauck R, Barsa J, Dwarakanath G, Dunbar E, Padda G. Multi-center evaluation of drug delivery accuracy with the Prometra intrathecal infusion pump. Pain Med 2009;10:124.

183. Berg A, Barsa J, Deer T, Dunbar E, Dwarakanath G, Padda G, Rauck R, Rosen S. Efficacy of morphine sulfate infusion via the Prometra ${ }^{\circ}$ intrathecal infusion pump. A prospective multicenter evaluation. Presented at: 5 th World Congress Institute of Pain; March 13-16, 2009; New York, NY.

184. Infusion systems. Information on file with the company.

185. Codman. Information on file with the company.

186. US Food and Drug Administration. PMA-premarket approval. www.accessdata.fda.gov/scripts/cdrh/cfdocs/cfPMA/PMA.cfm?ID=4499. Accessed May 8, 2009.

187. Rainov NG, Buchser E. Making a case for programmable pumps over fixed rate pumps for the management of fluctuations in chronic pain and spasticity: a literature review. Neuromodulation 2002;5:89-99.

188. Ilias W, Polain B, Buchser E, Demartini L. Patient-controlled analgesia in chronic pain patients: experience with a new device designed to be used with implanted programmable pumps. Pain Pract 2008;8:164-70.

189. Wallace MS, Rauck R, Fisher R, Charapata S, Ellis D, Dissanayake S. Intrathecal ziconotide for severe chronic 
pain: Safety and tolerability results of an open-label, long-term trial. Anesth Analg 2008;106:628-37.

190. Webster LR, Fisher R, Charapata S, Wallace MS. Long-term intrathecal ziconotide for chronic pain: an open-label study. I Pain Symptom Manage 2009;37:363-72.

191. Coderre TJ, Kumar N, Lefebvre CD, Yu JS. Evidence that gabapentin reduces neuropathic pain by inhibiting the spinal release of glutamate. J Neurochem 2005;94:1131-9.

192. Field MJ, Hughes J, Singh L. Further evidence for the role of the alpha(2)delta subunit of voltage dependent calcium channels in models of neuropathic pain. BrJ Pharmacol 2000;131:282-6.

193. Cheng JK, Chen CC, Yang JR, Chiou LC. The antiallodynic action target of intrathecal gabapentin: $\mathrm{Ca}+$ channels, KATP channels or N-methyl-d-aspartic acid receptors? Anesth Analg 2006;102:182-7.

194. Hayashida K, Obata H, Nakajima K, Eisenach JC. Gabapentin acts within the locus coeruleus to alleviate neuropathic pain. Anesthesiology 2008;109:107784.

195 Van Elstraete AC, Sitbon P, Mazoit JX, Benhamou D. Gabapentin prevents delayed and long-lasting hyperalgesia induced by fentanyl in rats. Anesthesiology 2008;108:484-94.

196. Lin JA, Lee MS, Wu CT, Yeh CC, Lin SL, Wen ZH, Wong CS. Attenuation of morphine tolerance by intrathecal gabap- entin is associated with suppression of morphine-evoked excitatory amino acid release in the rat spinal cord. Brain Res 2005;1054:167-173.

197. Granados-Soto V, Arguelles CF. Synergic antinociceptive interaction between tramadol and gabapentin after local, spinal, and systemic administration. Pharmacology 2005;74:200-8.

198. Sosnowski M, Yaksh TL. Role of spinal adenosine receptors in modulating the hyperesthesia produced by spinal glycine receptor antagonism. Anesth Analg1989;69:587-92.

199. Lee YW, Yaksh TL. Pharmacology of the spinal adenosine receptor which mediates the antiallodynic action of intrathecal adenosine agonists. J Pharmacol Exp Ther 1996;277:1642-8.

200. Karlsten R, Gordh T Jr. An A1-selective adenosine agonist abolishes allodynia elicited by vibration and touch after intrathecal injection. Anesth Analg 1995;80:844-7.

201. Rane K, Segerdahl M, Goiny M, Sollevi A. Intrathecal adenosine administration: A phase 1 clinical safety study in healthy volunteers, with additional evaluation of its influence on sensory thresholds and experimental pain. Anesthesiology 1998;89:1108-15.

202. Belfrage M, Segerdahl M, Arnér S, Sollevi $A$. The safety and efficacy of intrathecal adenosine in patients with chronic neuropathic pain. Anesth Analg 1999;89:136-42.
203. Canavero S, Bonicalzi V, Clemente M. No neurotoxicity from long-term $(\cdots, 3$ years) intrathecal infusion of midazolam in humans. I Pain Symptom Manage 2006;32:1-3.

204. Kroin JS, Ling ZD, Buvanendran A, Tuman KJ. Upregulation of spinal cyclooxygenase- 2 in rats after surgical incision. Anesthesiology 2004;100:364-9.

205. Yaksh TL, Horais KA, Tozier N, Rathbun M, Richter P, Rossi S, Grage M, Tong C, Meschter C, Cline JM, Eisenach J. Intrathecal ketorolac in dogs and rats. Toxicol Sci 2004; 80:322-34.

206. Eisenach JC, Curry R, Hood DD, Yaksh TL. Phase I safety assessment of intrathecal ketorolac. Pain 2002; 99:599604.

207. Manchikanti L, Boswell M, Singh V, Benyamin R, Fellows B, Abdi S, Buenaventura R, Conn A, Datta S, Derby R, Falco F, Erhart S, Diwan S, Hayek S, Helm S, Parr A, Schultz D, Smith H, Wolfer L Hirsch J. Comprehensive evidence-based guidelines for interventional techniques in the management of chronic spinal pain. Pain Physician 2009; 12:699-802.

208. Manchikanti, Singh V, Helm S, Schultz D, Datta S, Hirsch J. An introduction to an evidence-based approach to interventional techniques in the management of chronic spinal pain. Pain Physician 2009; 12:E1-33. 
